\title{
Cyclic Performance of Cross Restrained Steel Plate Shear Walls with Transverse Braces
}

\author{
Jin-Guang $\mathrm{Yu}^{1,2}$, Xiao-Tian Feng ${ }^{1}$, Bo Li ${ }^{3,4}$, Ji-Ping Hao ${ }^{1}$ \\ ${ }^{1}$ School of Civil Engineering, Xi'an University of Architecture and Technology, Xi'an 710055, China \\ ${ }^{2}$ State Key Laboratory of Western Architecture and Technology, Xi' an 710055, China \\ ${ }^{3}$ Department of Civil Engineering, University of Nottingham Ningbo China, Ningbo 315100, China \\ ${ }^{4}$ Ningbo Nottingham New Materials Institute, University of Nottingham Ningbo China, Ningbo, China
}

\begin{abstract}
This paper presents an investigation on the cyclic performance of cross restrained steel plate shear walls (SPSWs) with transverse braces. Transverse braces connecting to two columns are proposed to replace horizontal cross stiffeners on the infill steel plates. Effects of transverse braces on the performance of SPSWs are estimated through an experimental study and a finite element analysis. Two 1/3-scale two-story single-bay SPSW specimens, including one unstiffened SPSW and one cross restrained SPSW with transverse braces, are first tested under the quasi-static cyclic loading. Subsequently, finite element models for SPSWs are developed and verified by the test results. Cyclic performance of SPSW structures with different restrains for the infill steel plates are compared in terms of failure mode, loading capacity, energy dissipation capacity and stiffness degradation. Emphasis is given on the stress development and out-of-plane deformation of infill steel plates. The results show that use of transverse braces as the substitute of horizontal stiffeners enhances the loading capacity, energy dissipation capacity and ductility of SPSW structure. It is also effective to homogenize stress distribution and to restrain the out-of-plane deformation of infill steel plates, which finally decreases the additional bending moments applied to the columns. Compared with the unstiffened SPSWs, the maximum inward flexural deformation of columns in the cross restrained SPSWs with transverse braces is reduced by about $40.0 \%$. It has demonstrated that the proposed cross restrainers combined with transverse braces are effective in improving the cyclic performance of SPSWs.
\end{abstract}

Keywords: steel plate shear walls; cross restrainers; transverse braces; cyclic performance; finite element analysis

\section{Introduction}

Steel plate shear walls (SPSWs) have been extensively used as lateral load resisting systems in past few decades. They have excellent energy dissipation capacity, superior ductility and inherent redundancy [1-4]. For instance, the 35-story Kobe City Hall Tower built with SPSWs exhibits excellent seismic performance during the 1995 Kobe earthquake. SPSWs are also adopted in 75-story Tianjin Jinta Tower which is the world's tallest steel shear walled building [5]. Habashi and Alinia [6] conducted a numerical study on the interaction between the infill steel plates and the 
frame members and found that the infill steel plates are effective in resisting horizontal loads at the initial stage of loading. Once the tension field forms in the steel plate, the applied loads are mainly taken by the frame members. Lubell et al. [7] reported that columns with insufficient stiffness are prone to exhibit obvious inward flexural deformation under the tension field action in the steel plates. The occurrence of inward flexural deformation reduces the stresses in the middle of columns and increases the stresses near the ends of columns. This promotes the formation of plastic hinges and the failure of columns in an "hourglass" form, which is therefore named "hourglass effect". Yu et al. [3] and Li et al. [8] confirmed that the premature buckling of the infill steel plate and the premature failure of the frame columns decrease the ultimate loading capacity of the SPSWs. Thus, proper improvements are needed to prevent the premature failure of columns and further enhance the structural performance of SPSWs.

It is well-known that the stiffeners can provide effective out-of-plane restraint and axial support for the infill steel plate, which significantly improves the overall performance of SPSW structure [9]. Sigariyazd et al. [10] reported that the diagonally stiffened SPSW structure has good energy dissipation capacity and proposed a formula for estimating the loading capacity of diagonally stiffened SPSWs. Zhao et al. [11] analysed the stiffness and elastic critical stress of the stiffeners installed in SPSWs and proposed a formula for calculating the critical elastic shear strength of stiffened SPSWs. Chinese standard JGJ/T380 [12] specifies the requirements on the rigidity of stiffeners for SPSW. Yang et al. [13] conducted an elastic buckling analysis of the SPSWs stiffened by vertical tubes and correlated the compressive buckling strengths to the rigidities of stiffeners. Alavi and Nateghi [14] performed quasi-static tests on one unstiffened SPSW structure and two diagonally stiffened SPSW structures, and concluded that the stiffeners cannot increase the ultimate shear strength of SPSW structure. Sabouri-Ghomi and Mamazizi [15] carried out an experimental investigation on the stiffened SPSWs with two rectangular openings. Stiffeners were installed around the openings. Test results showed that the ultimate loading capacity, stiffness and energy dissipation are almost the same for the SPSWs regardless of the openings in steel plates. Guo et al. [16] investigated the influence of connecting form and arrangement of stiffeners on the seismic performance of SPSW structure. The study revealed that the cross stiffeners dividing the infill plate into small cell plates are effective in reducing the height-to-thickness ratio and delaying the buckling of the thin steel plate, which in turns to improve the loading capacity and stiffness of the infill steel plates. However, stiffeners installed through direct welding cause initial defects to the infill steel plates due to residual stress and welding distortion, which necessitates the development of new buckling restraining system for the infill steel plates in SPSWs.

To overcome the defects of the conventional welding stiffeners, several buckling restraining methods for infill steel plate of SPSW structure have been developed. For instance, precast concrete cover panels have been adopted to restrain the infill steel plates in SPSWs. This is a typical non-welded buckling-restrained SPSW (BR-SPSW) structure as concrete panels are connected with the infill steel plate by the bolts. Jin et al. [17] studied the seismic performance of precast concrete panel-restrained SPSWs structure with inclined slots on the infill steel plates, and found that the slotted infill steel plate can avoid transferring excessive forces to the boundary frame elements. Liu et al. [18] investigated the structural behaviour of BR-SPSWs with various height-to-width ratios 
for the steel plate, and proposed the simplified formulas to predict the yielding capacity of the BR-SPSWs with infill steel plates connected with beams only. Wei et al. [19] proposed a novel partially connected BR-SPSW, in which four corners of infill steel plates were bolted to the boundary frame elements by steel angles and gusset plates. A modified calculation method for shear strength of the partially connected BR-SPSW was also developed. In addition, Li et al. [8] and Tsai et al. [20] proposed a new restrained SPSW structure, which adopted pairs of the transverse braces sandwiching over both sides of the infill steel panels and connecting to the boundary columns. A design method for this SPSW structure was introduced and validated by quasi-static tests of two full-scale two-story narrow SPSWs. It was found that transverse braces can provide efficient horizontal support for the frame columns so that the horizontal forces in both columns can be alleviated. As a result, the inward flexural deformation of columns due to the tension field in steel plates can be prevented. Moreover, the use of the transverse braces in the narrow SPSWs increases the angle of tension field in relative to vertical line to be around $45^{\circ}$, which is beneficial to increase shear deformation of the steel plates. However, there is lack of sufficient investigation on the cyclic performance of restrained SPSWs, particularly for those with wide steel plates.

To overcome the limitations of welded stiffeners and to address the research needs on wide SPSWs with transverse braces, the cross restrainers combined with transverse braces are proposed to replace conventional stiffeners, and subsequently improve the cyclic performance of SPSW structure. An experimental study of two 1/3-scale two-story single-bay SPSW structure and a finite element analysis of three SPSW structure with different restraining configurations are conducted. Experimental results of SPSW structures in terms of failure mode, hysteretic behaviour and connection performance are presented. Following the validation of finite element models for SPSW structure, loading capacity, energy dissipation, stiffness degradation and infill-plate deformation of SPSW structure are further discussed.

\section{Cross Restrained SPSWs with Transverse Braces}

\subsection{Development of non-welded cross restrained SPSW with transverse braces}

In the conventional stiffened SPSW structures, stiffeners are normally installed on the infill steel plates through direct welding, which may cause high residual stress and large welding distortion in the steel plates and stiffeners. As seen in Fig. 1, welded stiffeners are prone to fail in the form of local buckling prior to the overall failure of the SPSWs, which weakens the buckling resistance for the infill steel plates. Thus, innovative non-welded cross restrainers are proposed as the replacement of the welded stiffeners in SPSWs to overcome the premature buckling of stiffeners installed on infill steel plates. Fig. 2 shows a schematic view of the proposed non-welded cross restrained SPSWs with transverse braces. The non-welded cross restrainers are installed on the both sides of the infill steel plate by the threaded bolts passing through the reserved holes and steel plate. The horizontal restrainer is connected to the columns while the vertical restrainer is disconnected with the beams. Thus, the proposed restrainers can restraint the out-of-plane buckling of infill steel plates as well as serve as the support for the frame columns. 


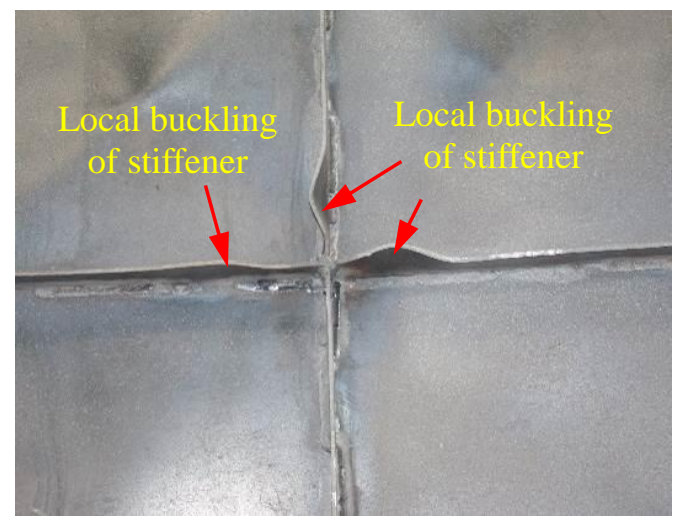

Fig. 1 Local buckling of welded stiffeners on infill steel plate

In the restrained SPSW structures [8], transverse braces connecting to the columns tend to restrain the out-of-plane buckling of the infill steel plate, which in turns to significantly contribute to horizontal resistance of the whole frame. As a result, the force demands from the frame columns can be properly reduced. The transverse braces can also divide the infill steel plate into several parts, which is suitable for the narrow SPSWs through reducing the width-to-height ratio of infill steel plates. It means that transverse braces are not applicable to the SPSWs with a high width-to-height ratio of the infill steel plates. It is recommended to install vertical restrainers for the SPSWs with a high width-to-height ratio of the infill steel plate.

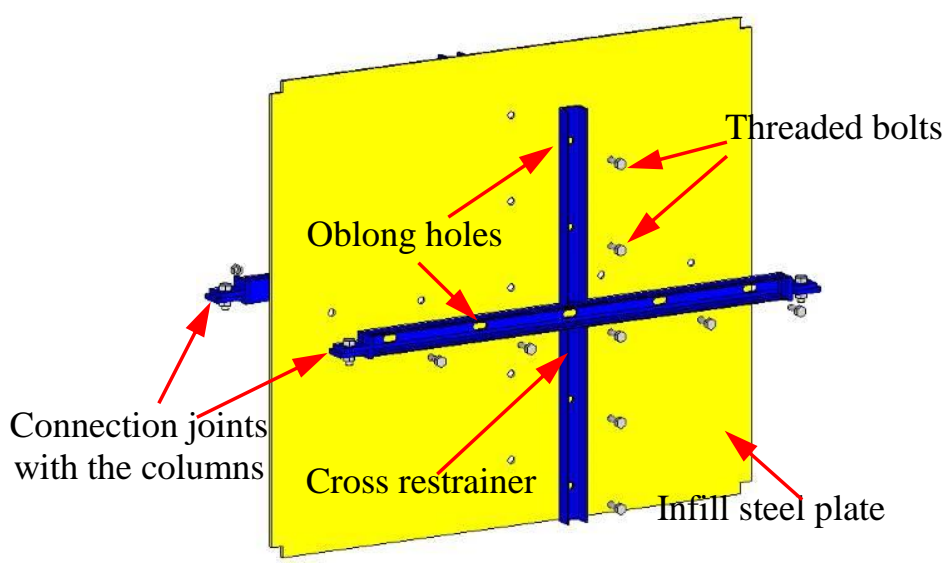

Fig. 2 Schematic view of non-welded cross restrainers combined with transverse braces

\subsection{Impact of transverse braces on the SPSW structure}

The use of cross restrainers with transverse braces in the SPSW structure can reduce the bending moments applied to the columns and the axial forces applied in the beams. Assuming the boundary elements remain essentially elastic under the action of fully yielding of steel plate, the forces transferring from infill steel plate to the frame members can be simplified as the uniform loads as shown in Fig. 3, and the inclination angle between the uniform load and the vertical axis is defined as $\alpha$. Thus, the magnitude of loads acting on the frame members can be estimated through the Equations (1) to (3). 


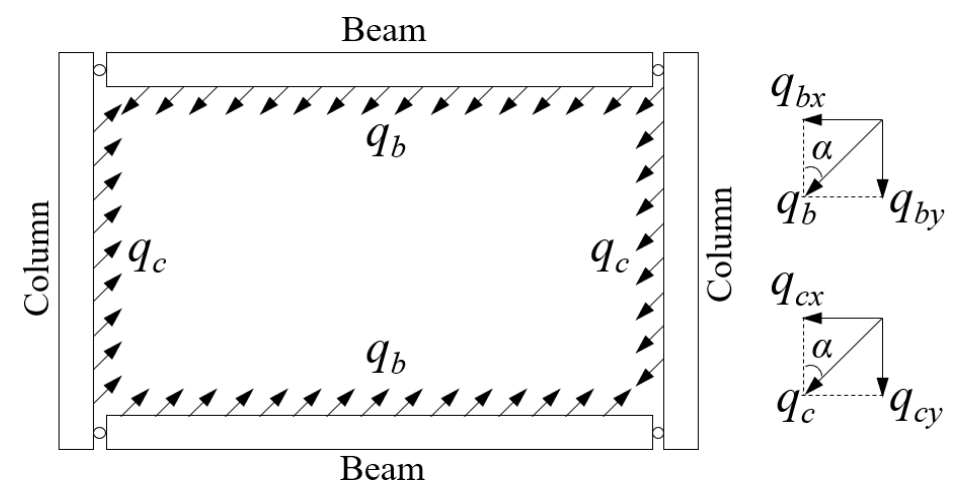

Fig. 3 Forces acting on the frame members when the infill steel plate fully yields

$$
\begin{aligned}
& q_{c y J}=q_{b x J}=f_{y p} \cos \alpha \sin \alpha \\
& q_{c x J}=f_{y p} t_{p} \sin ^{2} \alpha \\
& q_{b y J}=f_{y p} t_{p} \cos ^{2} \alpha
\end{aligned}
$$

The subscripts "c" and " $b$ " denote the forces acting on the column and the beam, respectively, and the subscripts " $y$ " and " $x$ " represent the vertical and horizontal force components, respectively. The subscript "J" stands for the infill steel plate at the $\mathrm{J}^{\text {th }}$ story. Besides, $f_{y p}$ and $t_{p}$ represent the yield stress and thickness of the infill steel plate, respectively.

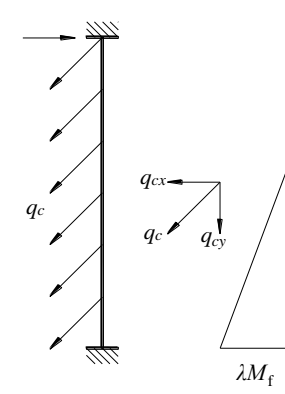

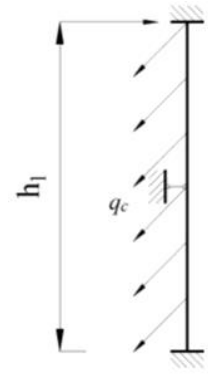

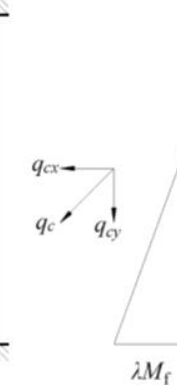

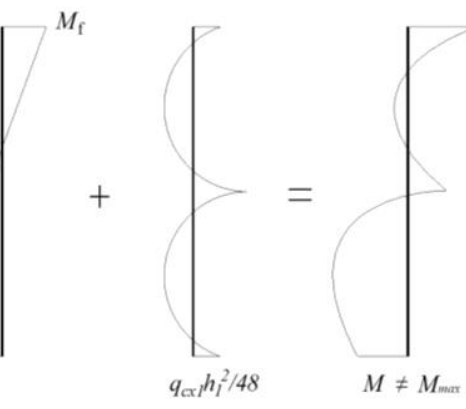

(b)

Fig. 4 Bending moments of the first-story columns in (a) conventional SPSWs and (b) proposed SPSWs with transverse braces

When SPSW structure is subjected to lateral loads, forces acting on the frame members can be computed through the superposition of two independent actions, including the lateral displacement of the frame and the tensile field of infill steel plate. According to the AISC code [21], the frame members are normally designed to be within the elastic range when the infill steel plates yield, unless plastic hinges form at the beam ends. As the frame columns are strongly fixed, plastic hinges will form at the column bases. As shown in Fig. 4, the superposition method is used to calculate the demand of bending moment for the first-story columns in two types of SPSW structures. Assuming the infill steel plate is fully yielding while the boundary columns remain essentially elastic, the demand on bending moment of the compressed first-story frame column $M_{p n}$ in the conventional SPSW structure can be estimated by Equation (4).

$$
M_{p n}=\frac{\lambda q_{c x 1} h_{1}^{2}}{2(\lambda+1)}-\frac{q_{c x 1} h_{1}^{2}}{12}=\left[\frac{\lambda}{2(\lambda+1)}-\frac{1}{12}\right] q_{c x 1} h_{1}^{2}
$$


The demand of bending moment in the compressed first-story frame column $M_{p m}$ in the proposed SPSW structure with transverse braces can be estimated by Equation (5).

$$
M_{p m}=\frac{\lambda q_{c x 1} h_{1}^{2}}{4(\lambda+1)}-\frac{q_{c x 1} h_{1}^{2}}{48}=\left[\frac{\lambda}{4(\lambda+1)}-\frac{1}{48}\right] q_{c x 1} h_{1}^{2}
$$

With the incorporation of transverse braces in SPSWs, the inclination angle of tension band $\alpha$ does not change significantly. Thus, when $\lambda \subset(1 \rightarrow \infty)$, the demand on the bending moment of the first-story frame columns can be reduced by $37.5 \%$ to $45 \%$.

Similarly, axial force of the $\mathrm{J}^{\text {th }}$-story beam in the conventional SPSW structure can be calculated by Equation (6).

$$
P_{b J n}=\frac{q_{c x J-1} h_{J-1}}{2}+\frac{q_{c x J-1} h_{J}}{2}
$$

With the presence of transverse braces, axial force of the $\mathrm{J}^{\text {th }}$-story beam can be reduced by $50 \%$ and is expressed in Equation (7).

$$
P_{b J m}=\frac{q_{c x J-1} h_{J-1}}{4}+\frac{q_{c x J-1} h_{J}}{4}
$$

Therefore, the proposed buckling restrainers with transverse braces can effectively improve the structural performance of SPSW structure as it reduces the bending moment applied to columns and the axial load of beams.

\section{Experimental Investigation on SPSWs}

Two 1/3-scale two-story single-bay SPSWs specimens, including one unstiffened SPSW (NBRP) and one cross restrained SPSW with transverse braces (CBRP-TB), are constructed and tested. The dimensions of frame members and infill steel plates in the two specimens are identical. The dimensions and layouts of the specimen CBRP-TB are shown in Fig. 5. Here, the upper two stories are the main structure while the bottom story serves as the anchorage for the upper structure. The bottom short story with the net height of $300 \mathrm{~mm}$ is designed to prevent the specimen from cracking at the column bases. As it serves as the fixed end for the main structure only, a $5 \mathrm{~mm}$ thick steel plate is adopted as the infill steel plate to enhance its lateral stiffness. The centre-to-centre distance of the frame columns is $1,350 \mathrm{~mm}$. The centre-to-centre distances of the first and second stories are

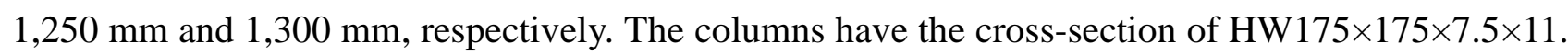
The cross-sections of the top beam and the other beams are $H N 300 \times 150 \times 6.5 \times 9$ and HN2 $00 \times 100 \times 5.5 \times 8$, respectively. The thicknesses of infill steel plates at the first and second stories are $3.3 \mathrm{~mm}$. Channel steel with the cross section of $\mathrm{C} 50 \times 37$ is adopted as the non-welded restrainers for the infill steel plates. Q235 steel with the characteristic yield strength of $235 \mathrm{MPa}$ was used for all the structural members. The frictional high-strength bolts with the yield strength of $900 \mathrm{MPa}$ and ultimate strength of $1000 \mathrm{MPa}$ are adopted as all connecting bolts. The measured materials properties of steels from different structural members are summarized in Table 1.

Transverse restrainers in the SPSWs are designed to resist buckling under the compressive forces transferring from the columns and to restrain the out-of-plane buckling of infill steel plate. As 
transverse restrainers installed on both sides of the infill steel plate are connected by the bolts, a combined cross section consisting of two transverse restrainers is used in the design. Compressive forces in the transverse braces are estimated to be half of horizontal component of the diagonal tension forces. In addition, both horizontal and vertical restrainers are checked to fulfil the requirement on out-of-plane stiffness for restraining the infill steel plates. This design is performed in accordance with the method for the post-buckling strength of beam webs

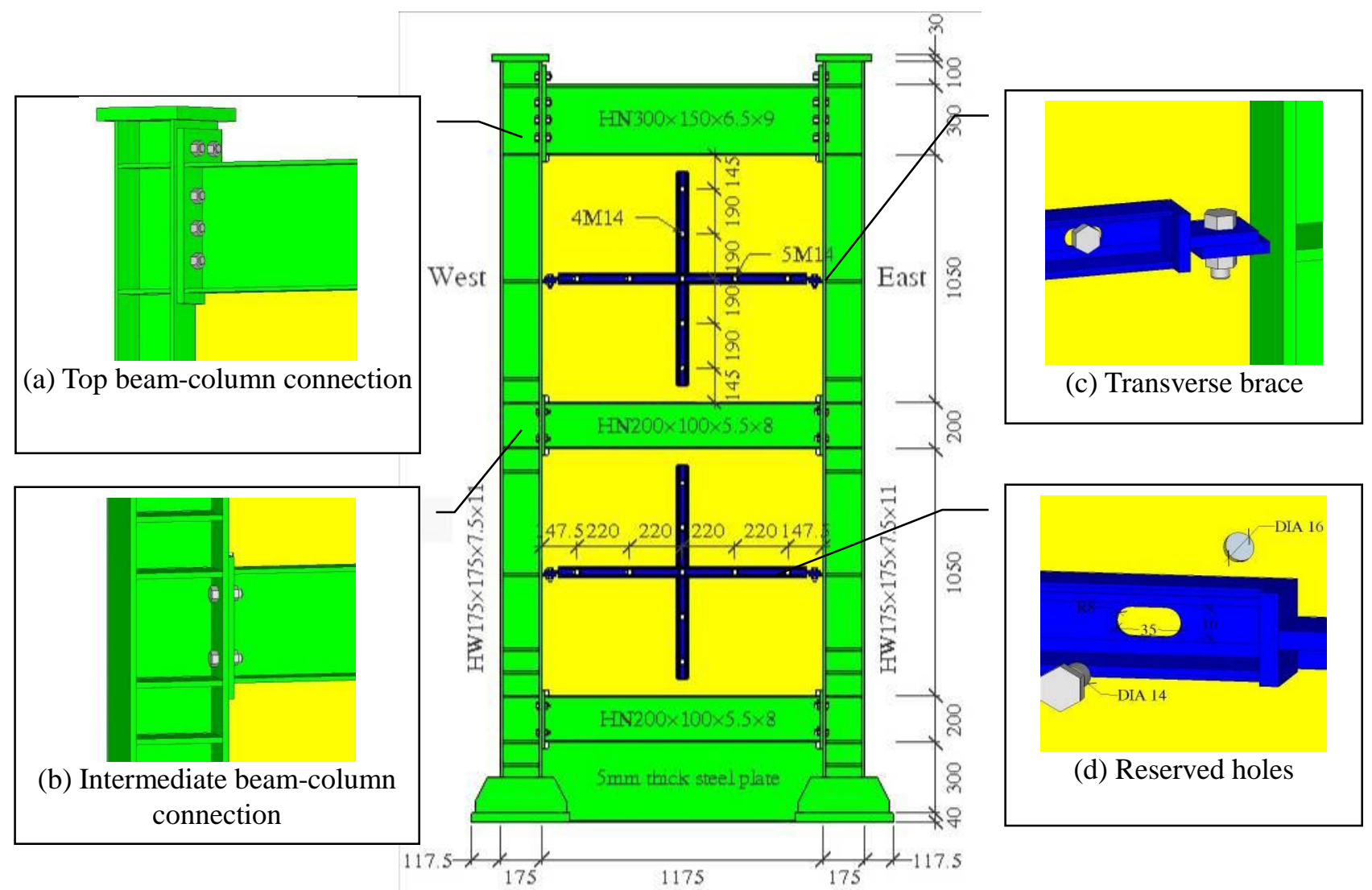

Fig. 5 Dimensions and details of cross restrained SPSWs with transverse braces

Table 1 Material properties of steels from different structural members

\begin{tabular}{|c|c|c|c|c|}
\hline Item & $\begin{array}{c}\text { Yield stress } \\
f_{y}(\mathrm{MPa})\end{array}$ & $\begin{array}{c}\text { Ultimate stress } \\
f_{u}(\mathrm{MPa})\end{array}$ & $\begin{array}{c}\text { Elongation } \\
\delta(\%)\end{array}$ & $\begin{array}{c}\text { Elastic modulus } \\
E(\mathbf{G P a})\end{array}$ \\
\hline HW $175 \times 175 \times 7.5 \times 11$ & 285.0 & 455.4 & 43.0 & 204.0 \\
\hline HN $300 \times 150 \times 6.5 \times 9$ & 323.2 & 465.3 & 44.0 & 204.0 \\
\hline HN $200 \times 100 \times 5.5 \times 8$ & 331.8 & 470.4 & 42.0 & 205.0 \\
\hline $3.3 \mathrm{~mm}$ thick steel plate & 345.3 & 521.8 & 36.0 & 210.0 \\
\hline $5 \mathrm{~mm}$ thick steel plate & 314.7 & 477.8 & 51.0 & 200.0 \\
\hline Cross restrainers & 335.1 & 463.1 & 37.0 & 201.0 \\
\hline
\end{tabular}

The beam-column connections on the top story and the other stories are shown in Figs. 5(a) and 5(b), respectively. In the cross restrained SPSW with transverse braces, the transverse braces are hinged to the columns as shown in Fig. 5(c), while the vertical restrainers are disconnected with the beams. The restrainers and/or braces are arranged symmetrically on both sides of the infilled steel plates. Incorporating cross restrainers with the transverse braces aims to restrain the 
out-of-plane deformation of the infill steel plate. However, the in-plane tension of the infill steel plate is not restrained. The C-channel steel members are bolted to the infilled steel plate with nine M14 high-strength bolts. The circular holes are drilled through the infilled steel plate while the slotted holes are reserved on the web of C-channel steel. As seen in Fig. 5(d), the slotted holes are arranged horizontally with a length of $35 \mathrm{~mm}$. The C-channels are free to move horizontally in relative to the infilled steel plate. Different from the frame members, the restraining members do not carry the force transferred from the diagonal tensile fields of infill steel plates. Thus, the restraining members have no influence on the height-to-thickness ratio of infill steel plate, which is different from the conventional stiffened SPSWs.

Fig. 6 shows the test setup for SPSW structure specimen. Constant axial loads are applied on the top of both columns by two $2000 \mathrm{kN}$ synchronous hydraulic jacks while lateral load is applied by a two-direction $1000 \mathrm{kN}$ MTS hydraulic actuator along the centre line of top beam. End plates are installed at the ends of top beam for connecting to the actuator. After imposing the constant axial load on the columns, lateral load is applied in loading control in the elastic stage and in displacement control after yielding [22]. In the load control stage, the lateral loading is applied with a $100 \mathrm{kN}$ increment and is cycled once at each loading level. The loading increment is reduced to $50 \mathrm{kN}$ when the specimen is approaching to the yielding. Afterwards, the lateral loading is applied in the mode of displacement control at $\Delta_{y}, 1.5 \Delta_{y}, 2 \Delta_{y}, 2.5 \Delta_{y} \ldots$ and is cycled three times at each displacement level. Here, yield displacement $\Delta_{y}$ is determined based on the load-displacement response of SPSWs or strains of steel at critical locations (e.g. the top and bottom of column). To prevent the out-of-plane deformation of the SPSW structure, a lateral supporting system is adopted as shown in Fig. 6. The test is stopped when the lateral load of the SPSW structure drops to $85 \%$ of the maximum loading.

Fig. 7 shows the arrangement of displacement transducers for the SPSWs specimens. Linear variable displacement transducers (LVDTs) are installed to monitor the slip of base beam (TC1), the relative slip between base beam and main structure (TC2) and the horizontal displacement of beams and columns (TC3 to TC10). LVDTs are also installed at the beam-column corners to estimate the rotation of beam-column joints (TW1 to TW8). According to the cosine theorem, the rotation of beam-column joints $\alpha$ can be calculated by Equation (8).

$$
\alpha=\arccos \left[\frac{2 \times 250^{2}-(250 \sqrt{2}+\text { disp })^{2}}{2 \times 250^{2}}\right]-\frac{\pi}{2}
$$

where, disp is the displacement measured by the inclined LVDTs. In addition, strain gauges are mounted on the end plates of intermediate-story beams to measure the local deformation of ends plates, reflecting the stress statues of the beam-column connections. 


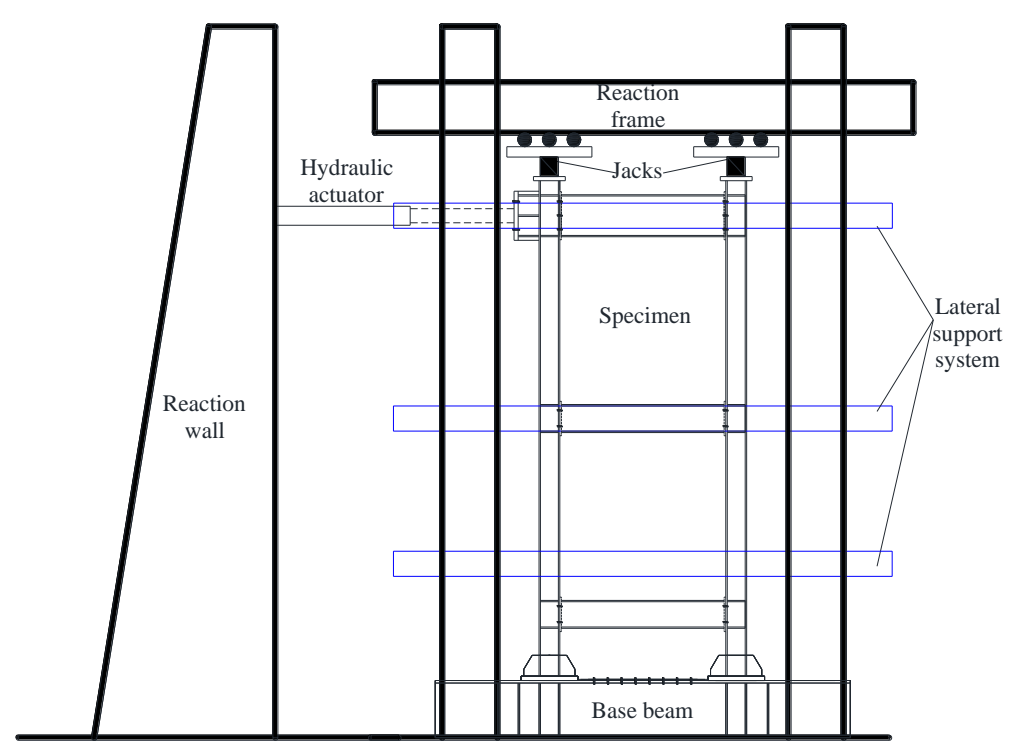

Fig. 6 Test setup for SPSW structure specimen

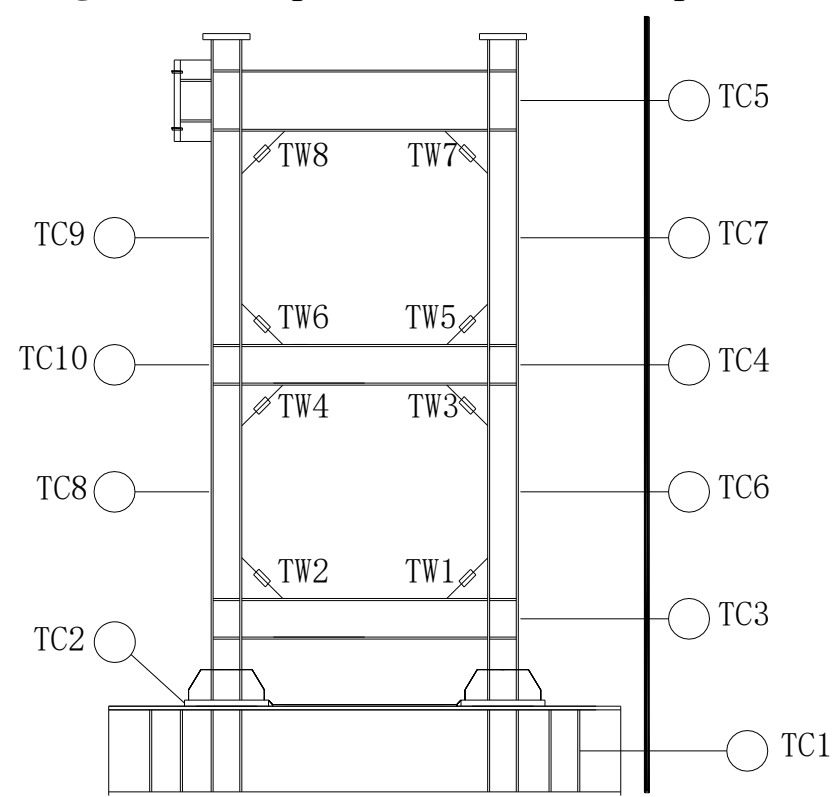

Fig. 7 Arrangement of displacement transducers

\subsection{General behaviour and failure modes}

Fig. 8 shows the failure modes of the specimens NBRP and CBRP-TB. Here, some subfigures are taken from the reverse side of the SPSW structure. When the lateral drift reached $0.3 \%$ in specimen NBRP, diagonal tensile bands formed in the first-story steel plate under the action of principal tensile stress. When unloading to the "zero displacement" followed by loading in the reverse direction, the out-of-plane deformation of the first-story steel plate was gradually reduced and even reversely developed, which is called "breathing effect". At such drift ratio, the out-of-plane deformation of steel plate could be completely recovered. At the drift ratio of $0.7 \%$, residual deformations were observed in the first-story steel plate of specimen NBRP. The peak load of specimen NBRP was attained at the drift ratio of $1.3 \%$ as the occurrence of tears in the first-story infill steel plate, as shown in Fig. 8(a). Meanwhile, obvious residual deformations were first observed in the second-story infill steel plate. The end plates of intermediate beams and beam-column connections rotated. At the drift ratio of $1.9 \%$, plastic hinges formed in the columns 
and the tensile bands of infill steel plate were fully developed. As a result, tears gradually occurred on the infill steel plate, which caused the local failure of steel plate, as shown in Figs. 8(b) and 8(c). Eventually, plastic hinges further developed at the ends of columns, and specimen NBRP failed in the form of in-plane bending-shear failure, as shownin Fig. $8(\mathbf{d})$.

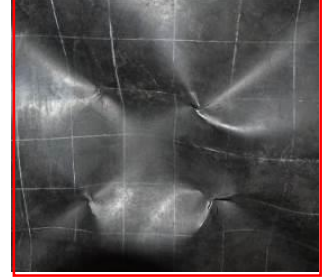

(a) $1.3 \%$ drift

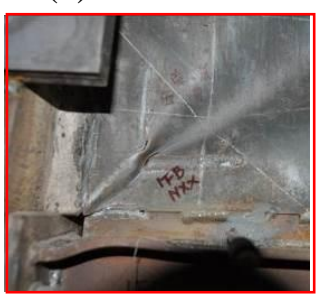

(b) $1.9 \%$ drift

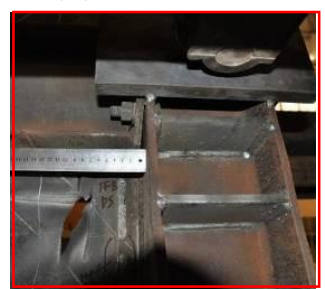

(c) $1.9 \%$ drift

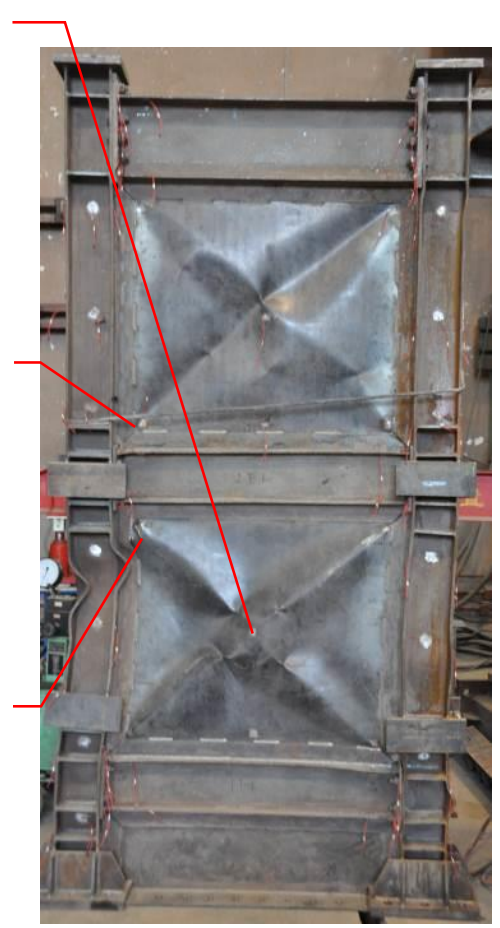

(d) Final failure

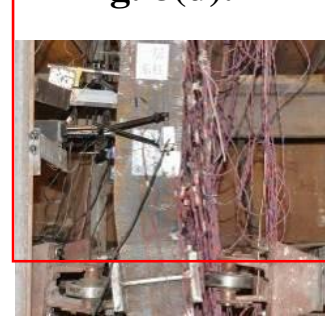

(e) $2.0 \%$ drift

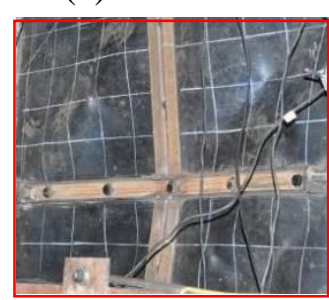

(f) $1.3 \%$ drift

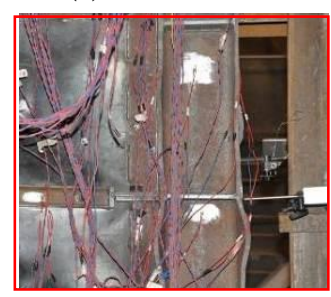

(g) $2.0 \%$ drift

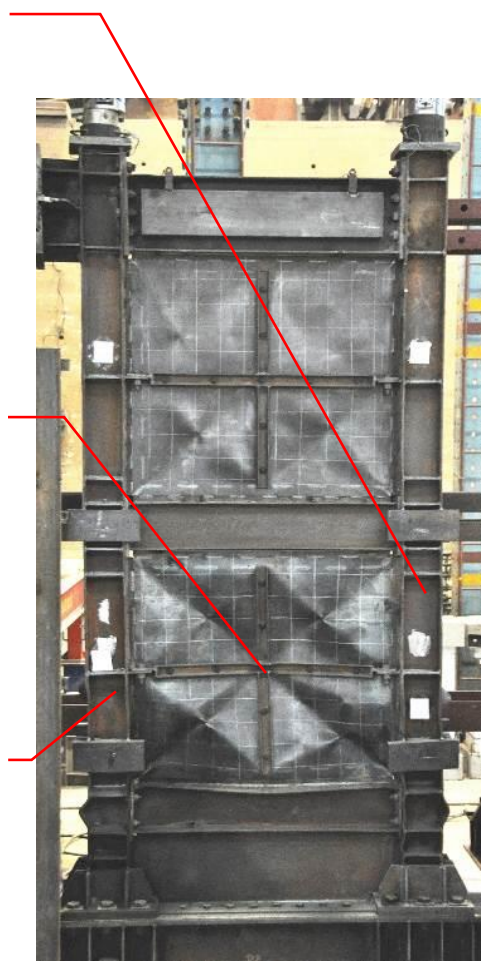

(h) Final failure

Fig. 8 Failure modes of specimens: (a-d) NBRP and (e-h) CBRP-TB

Specimen CBRP-TB shows a different failure mode as compared to specimen NBRP. There was no obvious residual deformation occurred until the lateral drift of SPSW structure reached $0.7 \%$. The local buckling of infill steel plates with residual deformations occurred on the first and second stories of SPSW structure. The peak load of specimen CBRP-TB was attained at the drift ratio of $1.3 \%$. As shown in Fig. Fig. 8(e), local buckling of transverse restrainers was observed in the flanges close to the intersection of cross restrainers, which weakened their restraining effect for steel plates. Slight out-of-plane deformation of steel plate at the first story occurred with obvious buckling in four cell plates at the second story. When the lateral drift of specimen CBRP-TB reached $1.5 \%$, the overall deformation of the first-story infill steel plate was significantly increased, causing obvious sound and the rotation of end plates. At the drift ratio of $2.0 \%$, local buckling of column flange occurred close to the connection with transverse braces, and the out-of-plane deformation of the column increased as shown in Fig. 8(e). Meanwhile, the tensile bands of infill steel plates were fully developed, followed with local failure of infilled steel plates due to the tears. With the further increase of drift, buckling extended from cell plates to the whole steel plate, followed with the development of plastic hinges in the middle of first-story columns as shown in Fig. 8(g). Finally, the specimen CBRP-TB failed in the form of in-plane bending-shear failure as shown in Fig. 8(h).

Fig. 9 shows the failure modes of first-story columns in SPSWs for both specimens NBRP and 
CBRP-TB. As seen in Fig. 9(a), west column at the first story of specimen NBRP exhibited obvious local buckling while east column showed slight in-plane flexural deformation. There were evident plastic hinges formed at the ends of columns with an obvious hourglass shape, eventually causing the failure of SPSW structures. The failure mode of the west and east columns at the first story of specimen CBRP-TB are shown in Fig. 9(b). Both columns in specimen CBRP-TB exhibited similar in-plane deformation and no obvious inward flexural deformations. It demonstrates that the setting of transverse braces in SPSWs has a significant restraining effect on the in-plane deformation of the columns, which can effectively avoid the "hourglass" phenomenon of frame columns.

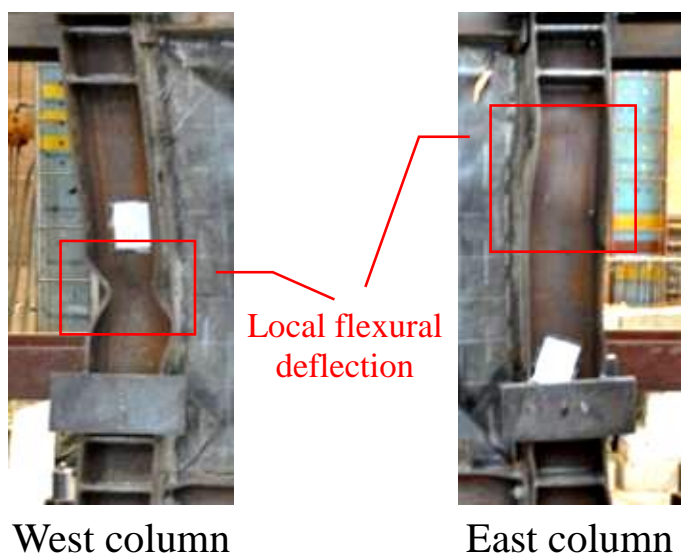

(a)

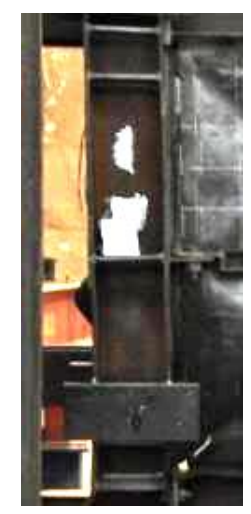

West column

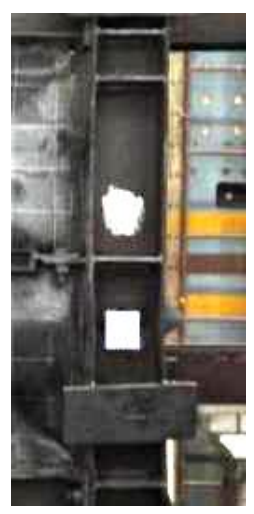

East column

(b)

Fig. 9 Failure modes of first-story columns in SPSWs for specimens (a) NBRP and (b) CBRP-TB

\subsection{Hysteretic behaviour}

The lateral load-displacement responses of the tested specimens are shown in Fig. 10(a). The hysteresis curves of both specimens have the following characteristics: (1) The load-displacement curves for both specimens change linearly at the initial stage of loading. (2) Due to the yielding of specimens, the unloading stiffness is slightly lower than the elastic stiffness. (3) When unloading to zero displacement and then loading reversely, the load-displacement curve gradually approaches the maximum load in the previous loading cycle and finally the hysteresis loop exhibits an obvious reverse-S shape with slight pinching phenomenon; (4) Compared with specimen CBRP-TB, hysteresis curve of specimen NBRP shows a more obvious pinching phenomenon.

Fig. 10(b) shows the comparison of typical hysteresis loops of specimens NBRP and CBRP-TB at the drift ratio of $2.0 \%$. Key points of the hysteresis loops are marked as $a-b-c-d-e-f$ according to the loading sequence. Among others, points $b$ and $e$ stand for the peak loads in the pull and push directions, respectively. Inflection points $f$ (or $c$ ) and $a$ (or $d$ ) represent the transfer of loading from pull (push) to push (pull) in a loading cycle, respectively. Generally, the enclosed area of hysteresis loop of specimen CBRP-TB is slightly larger than that of specimen NBRP. As seen in Fig. 10(b), the segment $e-f$ represents the unloading process from the reversed peak load to the "zero load". In this stage, the infill steel plates have been fully involved in resisting lateral load and the rigidities of the two specimens are almost the same. Segment $f$ - $a$ represents the loading process from the "zero load" to the "zero displacement". The steel plate experiences stretching, flattening, and reversely deforming during this process. It is found that specimen NBRP exhibits a loud sound while specimen CBRP-TB makes less sound during this process. As the tension field is not fully 
developed in specimen NBRP, the infill steel plate contributes limited stiffness to SPSWs and thus the lateral force is mainly taken by the frame. The cross restrainers in specimen CBRP-TB are able to restrain the buckling of steel plates, contributing to the lateral stiffness of SPSWs. As a result, the stiffness of specimen CBRP-TB is higher than that of specimen NBRP. In the segment $a-b$, the tension field is gradually formed in the specimen NBRP, and thus the infill steel plate is involved in the lateral resistance, reflecting the stiffness of the specimen NBRP increases rapidly. However, the stiffness of the specimen CBRP-TB remains slightly higher than that of the specimen NBRP. As the occurrence of local buckling of infill steel plate and channel steel restrainers, the lateral stiffness of the specimen CBRP-TB gradually degrades and ultimately becomes similar with that of the specimen NBRP.

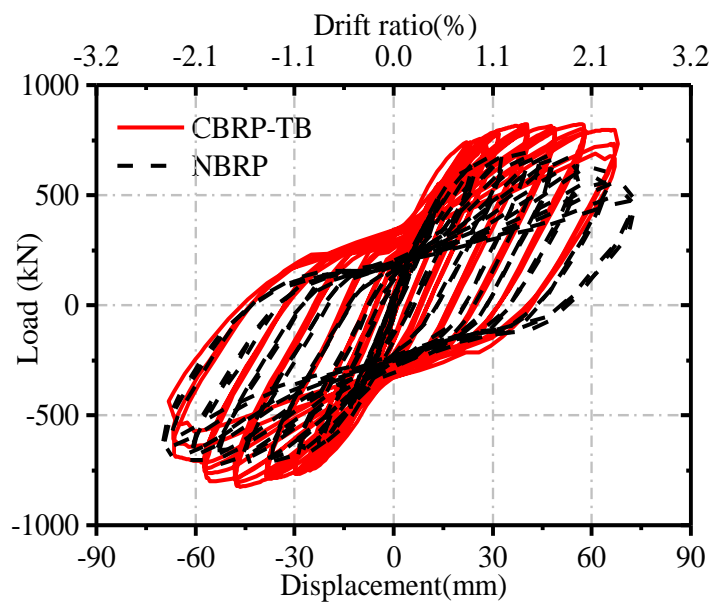

(a)

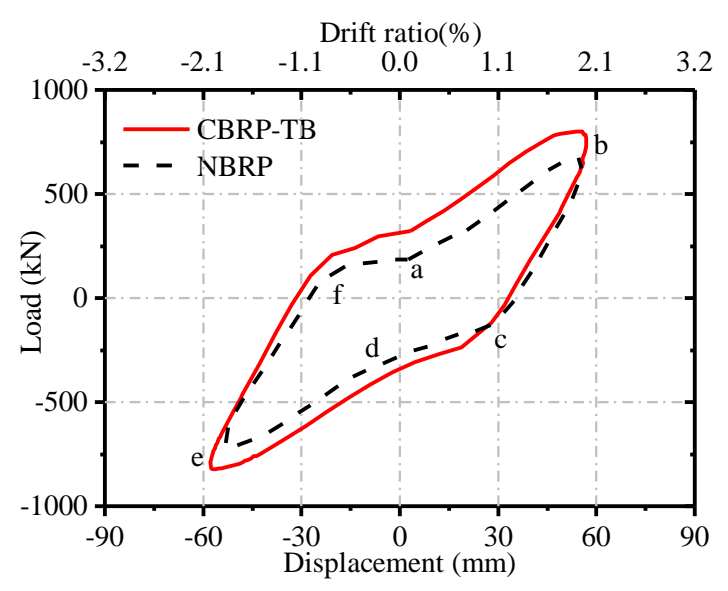

(b)

Fig. 10 Hysteretic curves of the experimental SPSW specimens: (a) whole loading cycles, and (b) first cycle at $2.0 \%$ drift

\subsection{Rotation and stress status of beam-column connections}

Fig. 11 shows the relationships between the lateral load and the rotations of beam-column connections for specimens NBRP and CBRP-TB. Here, the rotations of beam-column connection at the intermediate story are presented. It is readily seen that the rotations of beam-column connections are not obvious at the initial stage of loading. This is mainly attributed to the restrains from the infilled steel plates. Rotation of beam-column connections increases with the applied lateral load. The maximum rotations of beam-column connections at the intermediate story are $0.084 \mathrm{rad}$ and $0.012 \mathrm{rad}$ for specimens NBRP and CBRP-TB, respectively. It indicates that the incorporation of restrainers in SPSW structure reduces the rotation of beam-column connections by 85.7\%. It also means that beam-column connections in specimen NBRP requires a higher rotation capacity than that of specimen CBRP-TB. 


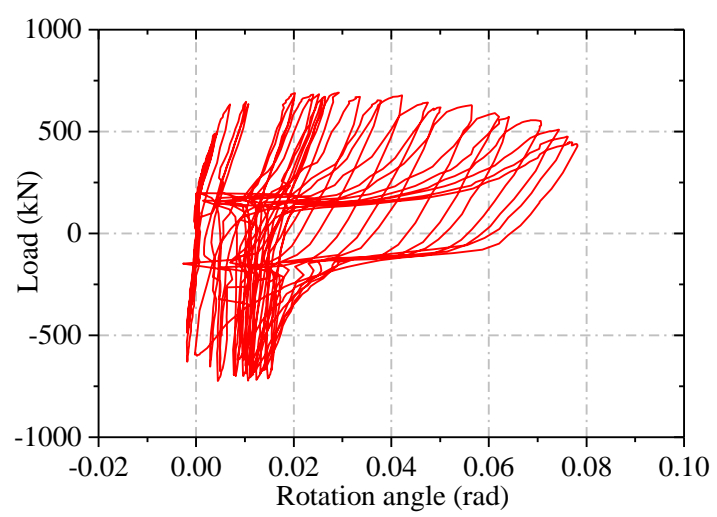

(a)

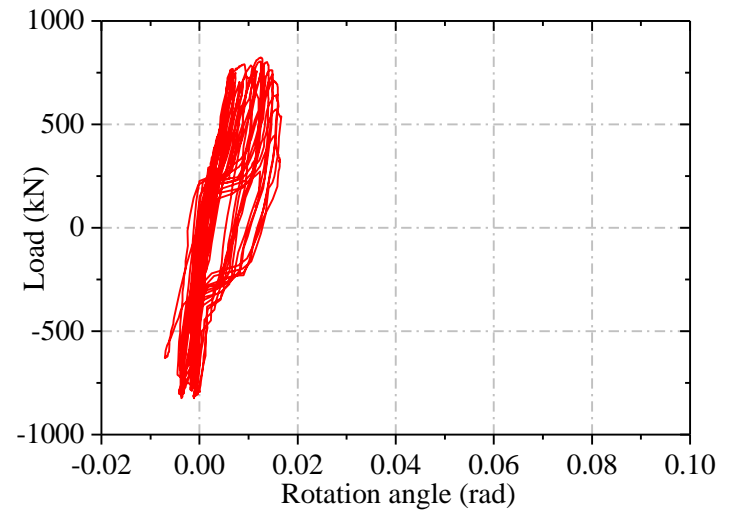

(b)

Fig. 11 Rotations of beam-column connections at the intermediate stories of specimens (a) NBRP and (b) CBRP-TB
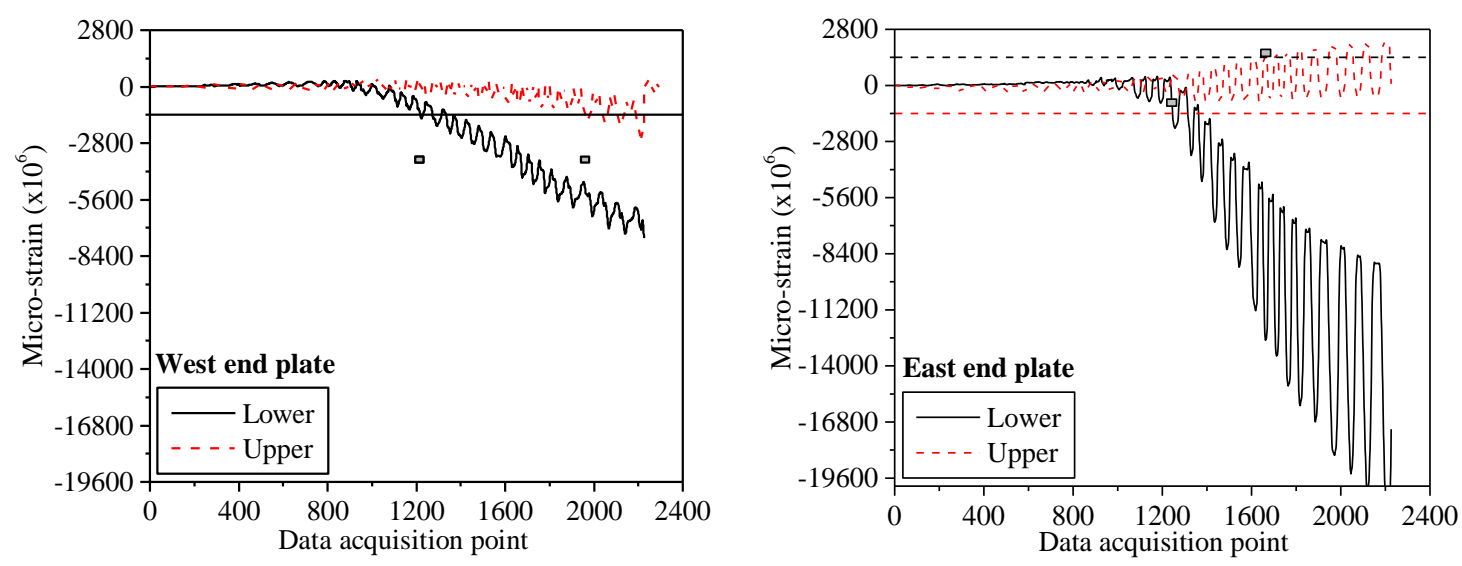

(a)
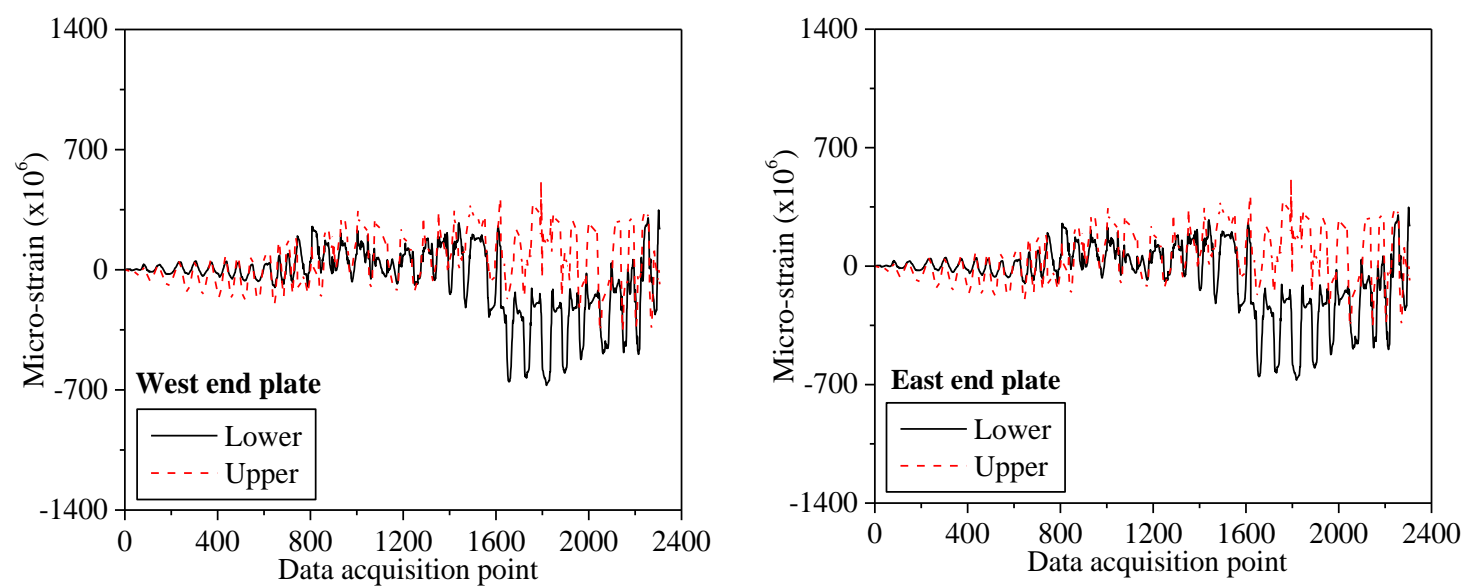

(b)

Fig. 12 Strains of end plates in the intermediate-story beams for specimens (a) NBRP and (b) CBRP-TB

Fig. 12 shows strains of end plates of intermediate-story beams against data acquisition points in both specimens NBRP and CBRP-TB. Yielding strain of steel materials at 1,400 micro-strains is also included in the figures. There is a significant difference in the strains of end plates between specimens NBRP and CBRP-TB. End plates in specimen NBRP yield while those in specimen CBRP-TB are within elastic range. Moreover, the lower and upper sides of east end plate in 
intermediate-story beam in specimen NBRP yield at the horizontal displacements of $40 \mathrm{~mm}$ and 56 $\mathrm{mm}$, respectively while those of the west end plate yield at the horizontal displacements of $40 \mathrm{~mm}$ and $70 \mathrm{~mm}$, respectively. It demonstrates that the lower side of the end plate yields earlier than the upper side. After yielding, the strain on the lower side of end plate keeps increasing and is much larger that of the upper side. This is mainly attributed to that the tension field in the first-story infill steel plate is formed earlier and more thoroughly in specimen NBRP. In summary, the use of cross restrainers with transverse braces is effective to alleviate the stress concentration at the beam-column connections in SPSW structure.

\section{Finite Element Model}

Finite element models (FEM) of SPSWs are established by the software ANSYS to investigate the effects of restrainers on the cyclic performance of SPSW structure. The infill steel plates, beams, columns, cross restrainers are modelled by element shell181. The contact element Conta173 and the target unit Targe170 are used to simulate the normal contact force between the non-welded restrainers and the infill steel plates. Meanwhile, the bilinear kinematical material model is used for the steel material with the consideration of Bauschinger effect due to cyclic loading. The tangential modulus of steel in the plastic stage is assumed to be $0.01 \mathrm{E}$, where E represents the modulus of elasticity. Besides, the von Mises yield criterion for steel is used in the FEM. The material properties of steel from different structural members are given in Table 1. The developed FEM are first validated by test results of specimens NBRP and CBRP-TB, followed with a parametric analysis. It is worth noting that the FEM of a cross restrained SPSW without connecting with the columns (i.e. specimen CBRP) is added in the numerical analysis for comparison. According to the principle of equivalent simplification, the weakening effect due to the small holes on the steel plate is not considered, and the node coupling method is used instead of establishing the bolted connection. Due to the slotted holes reserved on the web plate of the channel steel restrainers, the bolts could freely slide in the horizontal direction. Thus, the cross restrainers constraint the out-of-plane deformation of the infill steel plate but allow horizontal movements in relative to the infill steel plate. To achieve the above-mentioned structural performance in the FEM, the out-of-plane degrees of freedoms (DoFs), the in-plane vertical DoFs of the restrainers and the infill steel plate are coupled at the location of threaded bolts while the horizontal DoFs of them are released. The details of numerical model are shown in Fig. 13.

The vertical displacements (i.e. DoF $U_{y}$ ) of the nodes at the top plates of columns were coupled together, and the horizontal displacements (i.e. DoF $\mathrm{U}_{\mathrm{x}}$ ) of the nodes at the horizontal loading area were also coupled, so that stress concentration or local excessive deformation at the loading points could be avoided. In order to improve the effectiveness of the simulation and make sure that the FEM has the same boundary constraints as the test specimen, the bottom DoFs of the FE models were completely constrained to simulate the fixed support in the test. The out-of-plane displacements (i.e. DoF $\mathrm{U}_{\mathrm{z}}$ ) of the nodes at the position of lateral supports on each story were also constrained. The lateral supports were arranged along the height of $200 \mathrm{~mm}$ above the bottom beam and the centre lines of the intermediate and top beams, respectively. The specific locations are shown in Fig. 13. 


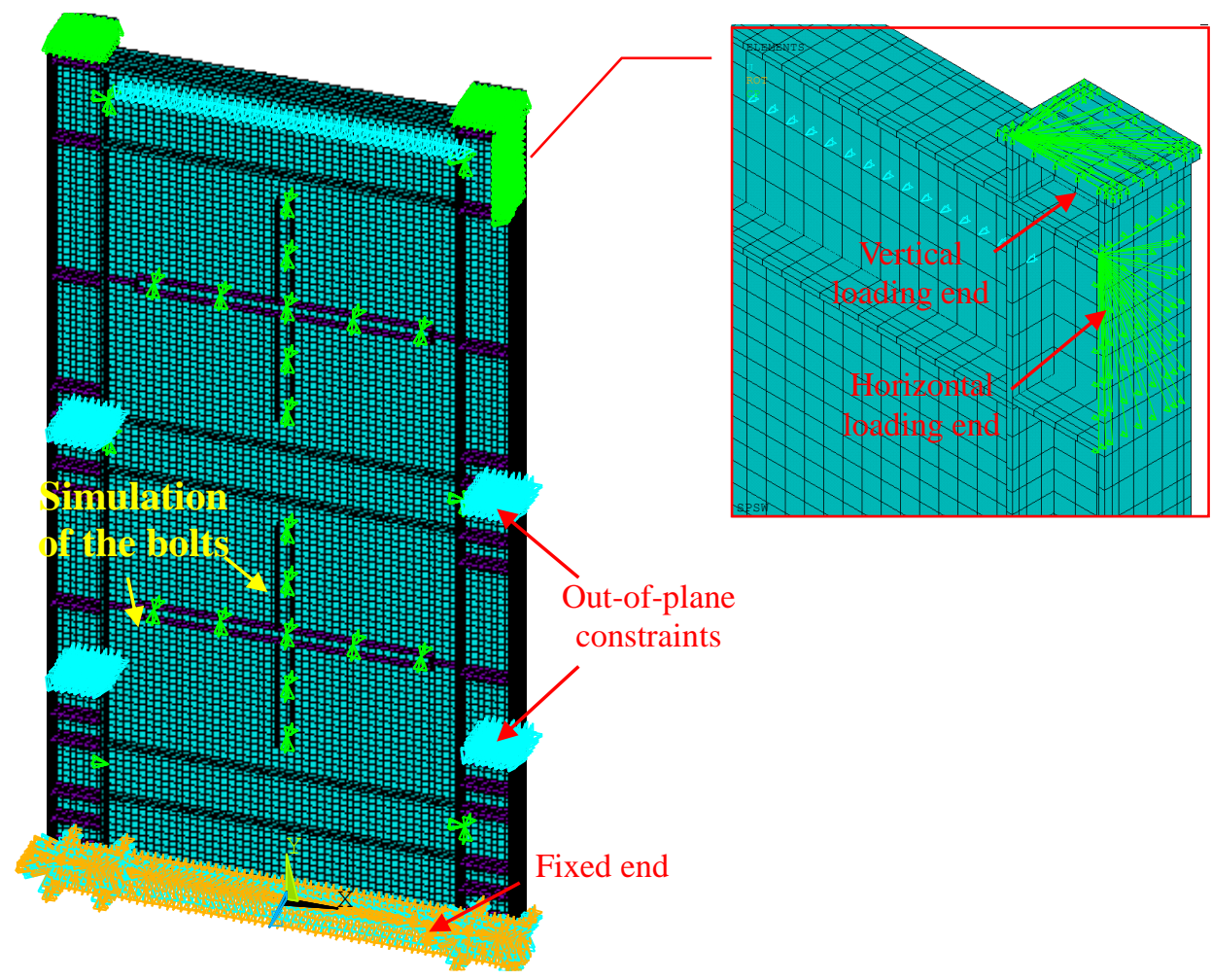

Fig. 13 Finite element model of SPSWs

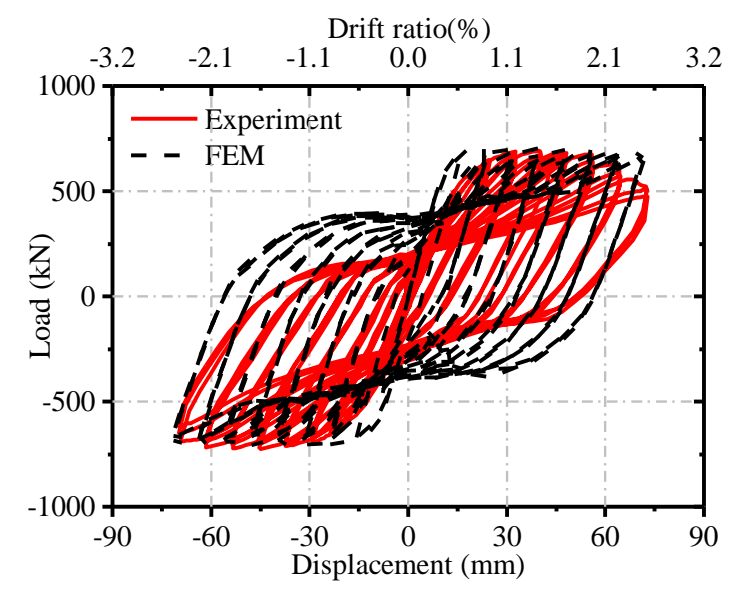

(a)

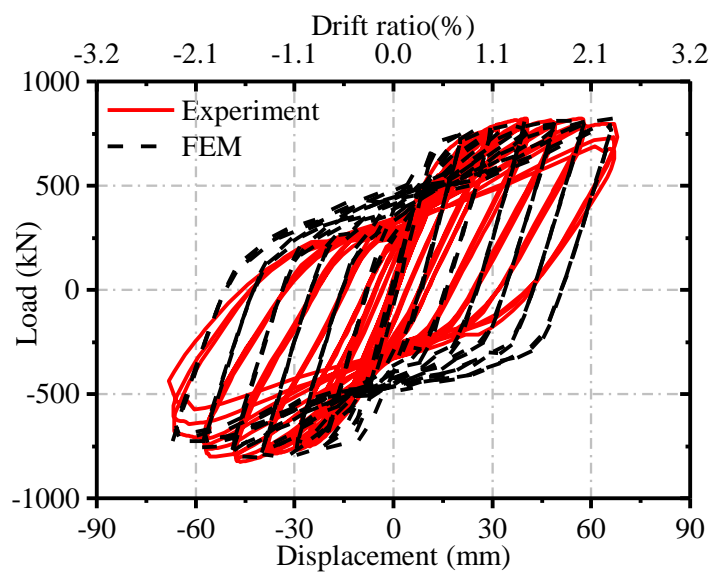

(b)

Fig. 14 Comparison of hysteretic curves between test results and FEM for specimens (a) NBRP and (b) CBRP-TB

\section{Numerical Results}

\subsection{Validation of FEM}

FEM of SPSWs is verified through comparing the hysteretic curves obtained from test results and finite element analysis as shown in Fig. 14. Both specimens NBRP and CBRP-TB are included in the comparison. Generally, the hysteretic curves obtained from FEM fit well with those of test results for both specimens, even if hysteretic curves from test results exhibit more pinching phenomenon. Stiffness and energy dissipation of SPSW structure in finite element analysis (FEA) are slightly higher than those in experimental study. However, the maximum load in each cycle for 
both specimens are properly captured in the FEM. It means that the envelops of hysteretic curves of test results and FEA are almost identical. As the failure of out-of-plane supports is not considered for specimen NBRP in the FEM, there is no post-peak descending segment in hysteretic curves. It is also noted that the initial stiffness obtained by the FEA is slightly lower than that of test results. This is mainly attributed to the non-uniform distribution of initial imperfection in experimental specimens, which makes the SPSW structure has higher stiffness than the idealized FEM with uniform initial imperfection. Generally, the FEM developed for SPSW structure is able to simulate the hysteretic behaviour of SPSW structure.

\subsection{Load carrying capacity and ductility}

Fig. 15 shows the hysteretic curves of specimens NBRP, CBRP-TB and CBRP from FEA. Summary of simulation results is given in Table 2. The yielding and peak loads of specimen CBRP-TB are $9.4 \%$ and $14.7 \%$ higher than those of specimen NBRP, respectively. It indicates that the installation of cross stiffeners combined with transverse braces are effective in enhancing the loading capacity of SPSWs. Comparing to specimen CBRP without transverse braces, the yielding and peak loads of specimen CBRP-TB are increased by $3.8 \%$ and $10.6 \%$, respectively. It demonstrates that the transverse braces connecting to two columns also contribute the lateral resistance of the SPSWs. In the FEM, buckling of the columns occurred under the combined action of axial load and bending moment for specimen CBRP, which reduces its loading capacity when the lateral drift reaches $2.0 \%$. It is necessary to hinge transverse braces to the columns. Differently, hysteretic curve of specimen CBRP-TB keeps going up without obvious descending as the lateral displacement increases. Cross buckling restrained SPSWs with transverse braces exhibits the best hysteretic performance in terms of loading capacity and post-peak loads.

The displacement ductility ratio $\mu$ of SPSW structures is computed by using Eq. (9). Here, the general yielding method [23] is adopted to determine the yield displacement $\left(\Delta_{\mathrm{y}}\right)$ based on the envelops of hysteretic curves, as shown in Fig. 16. $\Delta_{\mathrm{u}}$ is the ultimate displacement corresponding to the load of 0.85 of the peak load in the post-ultimate stage.

$$
\mu=\Delta_{u} / \Delta_{y}
$$

The displacement ductility of experiment specimens NBRP and CBRP-TB are 3.6 and 3.5, respectively. Ductility of specimen CBRP-TB is around $2.8 \%$ lower than that of specimen NBRP. It indicates that influence of restrainers on the ductility of SPSW structure is marginal. 


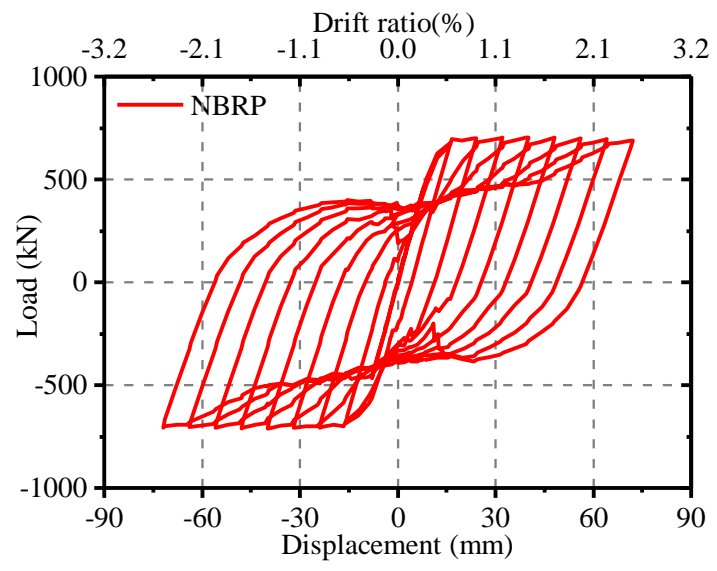

(a)

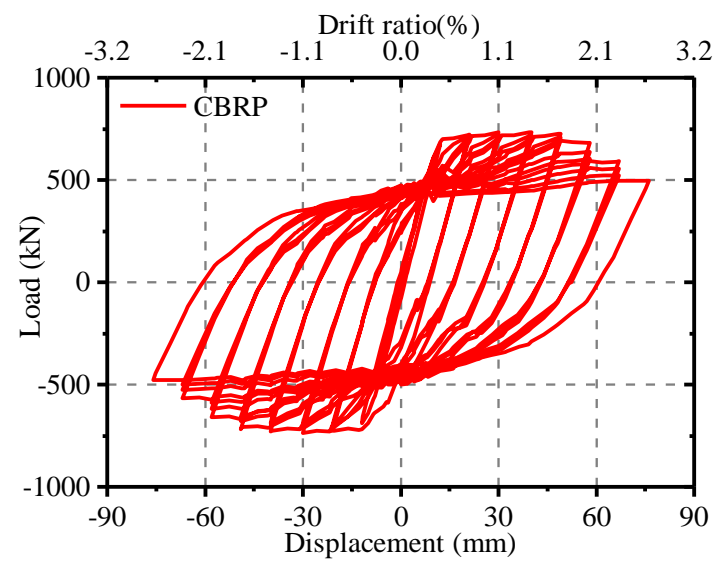

(c)

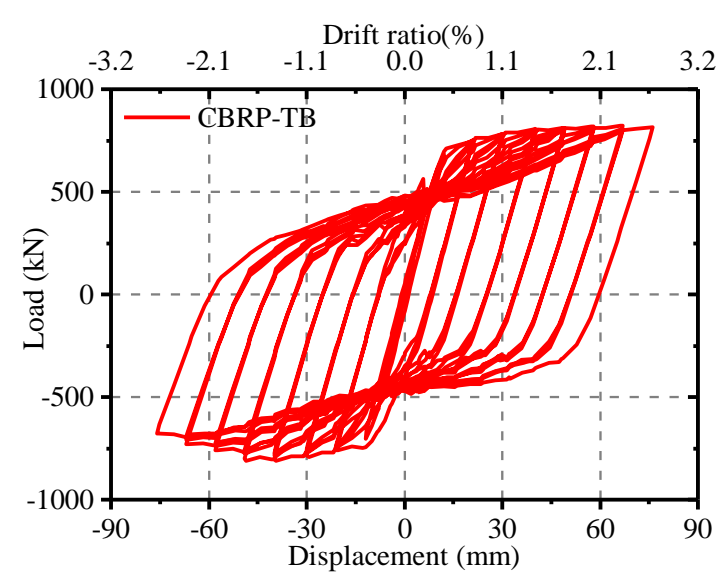

(b)

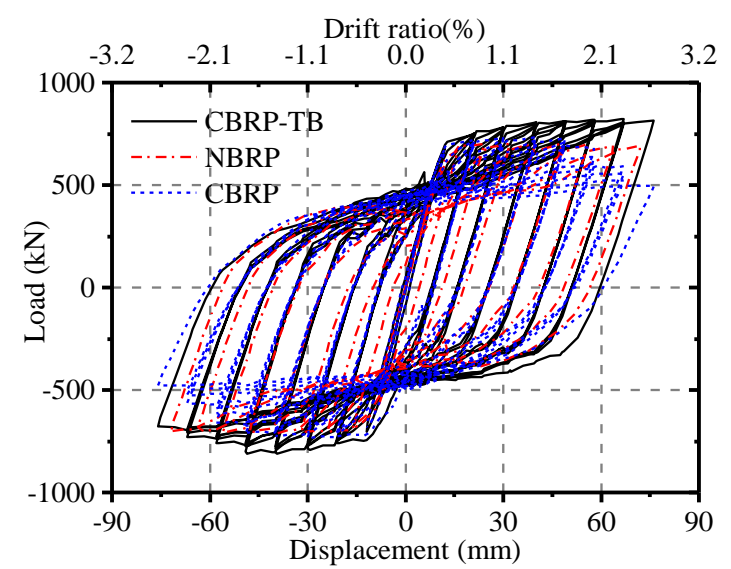

(d)

Fig. 15 Comparison between the hysteretic curves of FE models
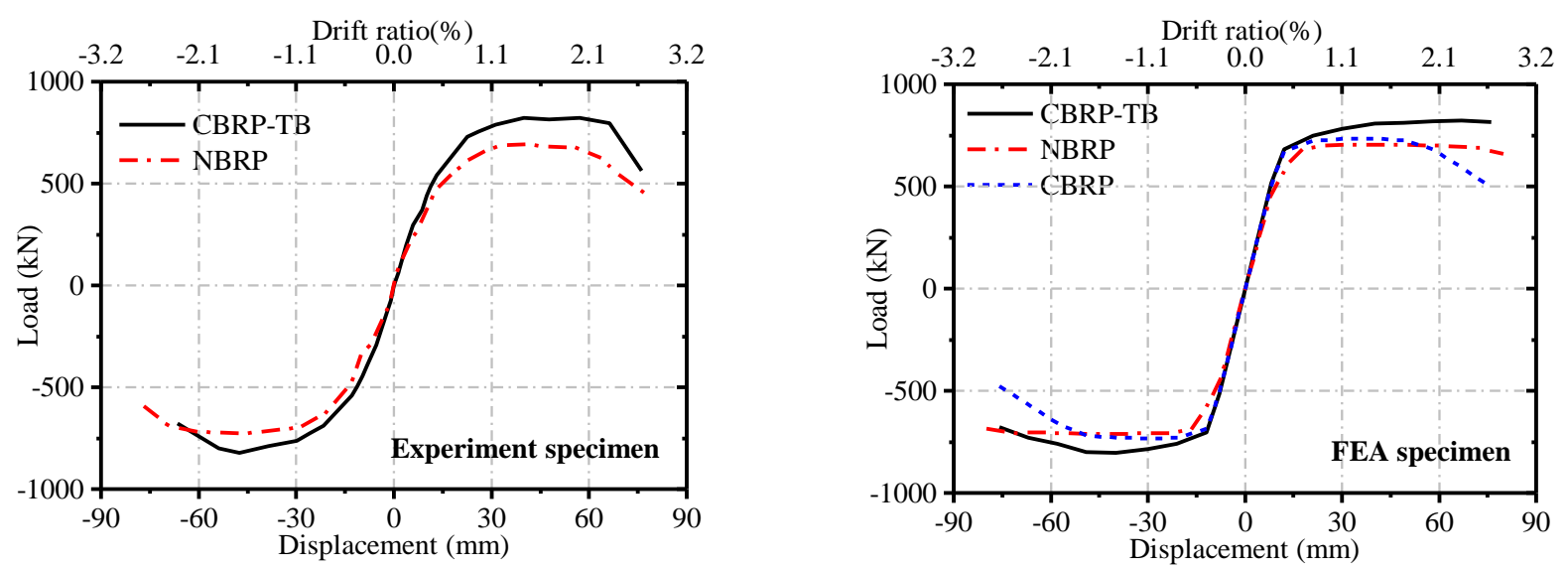

Fig. 16 Envelops of hysteretic curves obtained from (a) experiment and (b) FEA 
Table 2 Summary of experimental and numerical results

\begin{tabular}{|c|c|c|c|c|c|}
\hline \multirow{2}{*}{ Specimen } & Item & $\begin{array}{c}\text { Yield displacement } \\
\boldsymbol{\Delta}_{\boldsymbol{y}}(\mathbf{m m})\end{array}$ & $\begin{array}{c}\text { Ductility } \\
\text { factor } \boldsymbol{\mu}\end{array}$ & $\begin{array}{c}\text { Yield load } \\
(\mathbf{k N})\end{array}$ & $\begin{array}{c}\text { Peak load } \\
(\mathbf{k N})\end{array}$ \\
\hline \multirow{3}{*}{ NBRP } & Test & 19.8 & 3.6 & 590.7 & 708.2 \\
\cline { 2 - 6 } & FE & 14.9 & - & 650.8 & 708.3 \\
\cline { 2 - 6 } & FE/Test & 0.753 & - & 1.102 & 1.000 \\
\hline \multirow{2}{*}{ CBRP } & FE & 12.8 & - & 685.5 & 734.5 \\
\cline { 2 - 6 } & Test & 20.4 & - & 711.9 & 822.5 \\
\cline { 2 - 6 } & FE & 14.7 & - & 1.048 & 0.988 \\
\hline \multirow{2}{*}{ Ratio } & $\begin{array}{c}\text { FBRP-TB FE/ } \\
\text { CBRP FE }\end{array}$ & 0.721 & - & 1.038 & 1.106 \\
\cline { 2 - 6 } & CBRP-TB FE/ & 1.148 & - & 1.094 & 1.147 \\
\hline
\end{tabular}

\subsection{Energy dissipation and stiffness degradation}

Energy dissipation and stiffness degradation of SPSW structures are given in Table 3. Energy dissipation capacity of each loading level is determined by the enclosed area of hysteresis loop at the first cycle of this loading level. Peak stiffness is calculated by the slope of secant line passing through the points of peak loads at the first cycle of each loading level. In general, energy dissipation of specimen NBRP is smaller than that of specimens CBRP and CBRP-TB at each loading stage. For instance, the specimens CBRP and CBRP-TB have the similar energy capacity which is $32.2 \%$ higher than that of the specimen NBRP at the horizontal displacement of $12 \mathrm{~mm}$. This is mainly contributed to the restraining effect of cross restrainers installed on the infill steel plates. As horizontal displacement increases, the energy dissipation of specimens CBRP-TB and CBRP are much higher than that of specimen NBRP at the same displacement level. The maximum increase ratio of energy dissipation of SPSWs reaches $38.0 \%$ after the installation of transverse braces. The results show that the cross restrained SPSW structure with transverse braces has good energy dissipation capacity.

Stiffness of specimens CBRP and CBRP-TB are slightly higher than that of specimen NBRP. Specifically, the restrainers increase the lateral stiffness of the SPSW structure by $7.5 \%$ at the displacement of $12 \mathrm{~mm}$. However, when the lateral drift reaches $1.7 \%$ (i.e. at the horizontal displacement of $49 \mathrm{~mm}$ ), the strengthening effect of the cross restrainers on the lateral stiffness is decreased. The lateral stiffness of specimens NBRP and CBRP degrades to the same level which is $11 \%$ lower than that of specimen CBRP-TB. In summary, specimens CBRP-TB has the optimal energy dissipation capacity and lateral stiffness, followed by specimens CBRP and NBRP in sequence. 
Table 3 Energy dissipation and stiffness degradation of SPSW FE models

\begin{tabular}{ccccccc}
\hline \multirow{2}{*}{$\begin{array}{c}\text { Loading } \\
\text { level } \\
(\mathbf{m m})\end{array}$} & $\begin{array}{c}\text { Energy } \\
\text { dissipation } \\
\mathbf{( k N \cdot m m )}\end{array}$ & $\begin{array}{c}\text { Peak } \\
\text { stiffness } \\
\mathbf{( k N / m m )}\end{array}$ & $\begin{array}{c}\text { Energy } \\
\text { dissipation } \\
\mathbf{( k N \cdot m m )}\end{array}$ & $\begin{array}{c}\text { Peak } \\
\text { stiffness } \\
(\mathbf{k N / m m})\end{array}$ & $\begin{array}{c}\text { Energy } \\
\text { dissipation } \\
(\mathbf{k N} \cdot \mathbf{m m})\end{array}$ & $\begin{array}{c}\text { Ptiffness } \\
\mathbf{( k N / m m})\end{array}$ \\
\hline 12 & 1648.1 & 53.0 & 2162.5 & 56.8 & 2160.2 & 57.8 \\
21 & 16171.5 & 33.2 & 18309.4 & 34.5 & 19167.9 & 35.9 \\
30 & 28606.7 & 23.7 & 29043.5 & 24.5 & 34936.2 & 26.1 \\
40 & 43915.6 & 17.9 & 48425.8 & 18.3 & 53841.7 & 20.1 \\
49 & 56637.0 & 14.7 & 67488.9 & 14.8 & 70512.6 & 16.5 \\
58 & 67044.2 & 12.4 & 83376.4 & 11.5 & 93610.4 & 13.6 \\
67 & 88362.2 & 10.8 & 93151.5 & 8.6 & 104924.9 & 11.6 \\
76 & 105730.3 & 9.5 & 98596.5 & 6.4 & 119641.9 & 9.8 \\
\hline
\end{tabular}

\subsection{Stress development in SPSWs}

The stress distribution of SPSWs under drift ratios of $0.4 \%, 1.3 \%$ and $2.0 \%$ for specimens NBRP, CBRP and CBRP-TB are shown in Fig. 17. With the increase of the lateral drift, the stresses of the infill steel plates increase gradually till the formation of diagonal tensile bands. The yielding in steel plates also extends to the frame columns. When the lateral drift reaches $0.4 \%$, the maximum stress in the specimen NBRP occurs along the diagonal areas of the infill steel plates at both stories. Partial tensile bands enter into the plastic stage with a significant out-of-plane buckling. The stress of the first-story infill plate is higher than that of the second-story infill steel plate. Meanwhile, the stress of the infill steel plate is higher than that of the frame members. Partial zones of the column flange and web also enter the plastic stage. When the lateral drift reaches $1.3 \%$, the tensile bands along the two diagonal directions extend with a larger plastic area. Besides, the fracture appears at the bottom corners of the infill steel plate which is reflected by stress reaching the tensile strength. Moreover, the inward flexural deformation of the columns becomes larger with the further development of stress. When the lateral drift reaches $2.0 \%$, the infill steel plates develop into the hardening stage as the stress increases slightly. The stress distribution of the infill steel plate at the lateral drift of $2.0 \%$ is almost the same as that with the lateral drift of $1.3 \%$. Finally, the yielding zones at the end of columns gradually develop into the plastic hinges and the obvious inward flexural deformation of the columns is caused by the action of tension field.

As the non-welded restrainers do not serve as the anchoring ends of the infill steel plates, they are mainly subjected to the normal force perpendicular to the steel plates. Thus, there is no in-plane load transferring between the restrainers and the infill steel plate. When the lateral drift reaches $0.4 \%$, most zones of the infill plates along the tensile diagonal direction yielded. Especially, on the first-story infill plate of the specimen CBRP-TB, six obvious tensile bands formed along the diagonal directions and extended along the full infill plate as well as the small cell plates. The stress in the infill plate is greater than that of the boundary frame members as the presence of restrainers reduces the additional force on the column caused by diagonal tension fields. In particular, there are few yielding zones on the columns of the specimen CBRP-TB. For the specimen CBRP-TB, when 
the lateral drift reaches $1.3 \%$, the area of plastic zones is increased with the stress on the infill plate. Besides, the first and second infill steel plates are fully yielding, and the bottom corners of the infill plates reach the tensile strength. The tensile bands are gradually developed not only along the entire diagonal direction of the infill steel plate but also along the local diagonal direction in the cell plates. Under the cyclic load, the tensile bands along the diagonal directions expand due to the residual deformation. However, with the restraining effect of cross buckling restrain stiffeners, the buckling mode of infill steel panels is converted from the global buckling deformation to the local buckling deformation in the cell plates. Besides, due to the high order buckling mode, accumulated residual deformation and cyclic damage, the stress distribution of the tension field is not uniform, which further causes the complicated stress distribution of the infill plate. For specimens CBRP and CBRP-TB, the stress level and yielding area of the steel columns are still lower than those of specimen NBRP. At the same lateral drift, the specimen CBRP has formed plastic hinges at the column ends with the significant inward flexural deformation in the middle of the columns. When the lateral drift reaches $2.0 \%$, the infill steel plates of specimens CBRP and CBRP-TB enter the hardening stage and the stresses in both diagonal directions increased. In addition, the stress distribution modes are basically unchanged while the stress development processes of the frame columns are different. The plastic hinges on the columns of the specimen CBRP-TB are formed at the lower side of the connections between first-story transverse braces and frame columns, while plastic hinges in the specimen CBRP form at the column ends. In general, the frame and infill steel plates of specimen CBRP-TB work cooperatively and the infill plates lose lateral resistance before the failure of frame columns, which conforms to the design concept of dual seismic resistance, indicating that specimen CBRP-TB is an excellent lateral force resisting system. Specimen CBRP-TB also has the optimal structural performance in making full use of infill plates to resist lateral load and delaying the stress development of the frame columns.
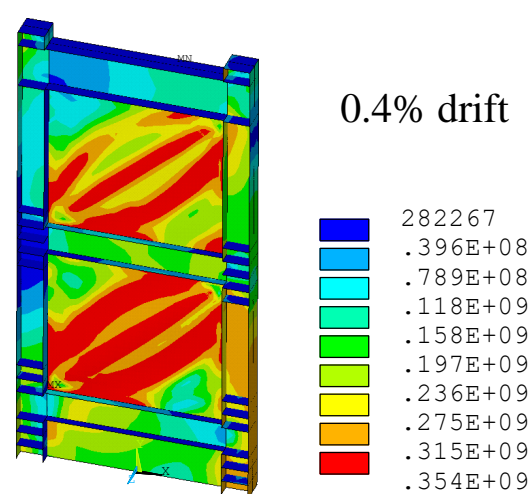
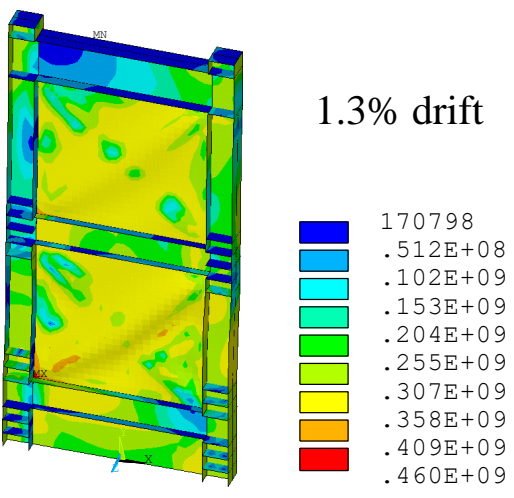

$1.3 \% \mathrm{drift}$

(a)

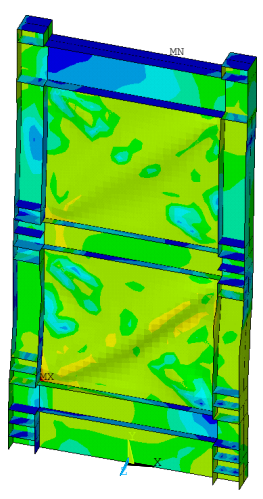

$2.0 \%$ drift

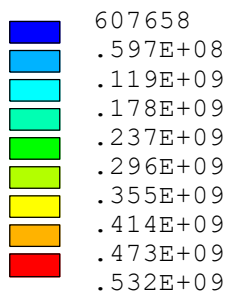



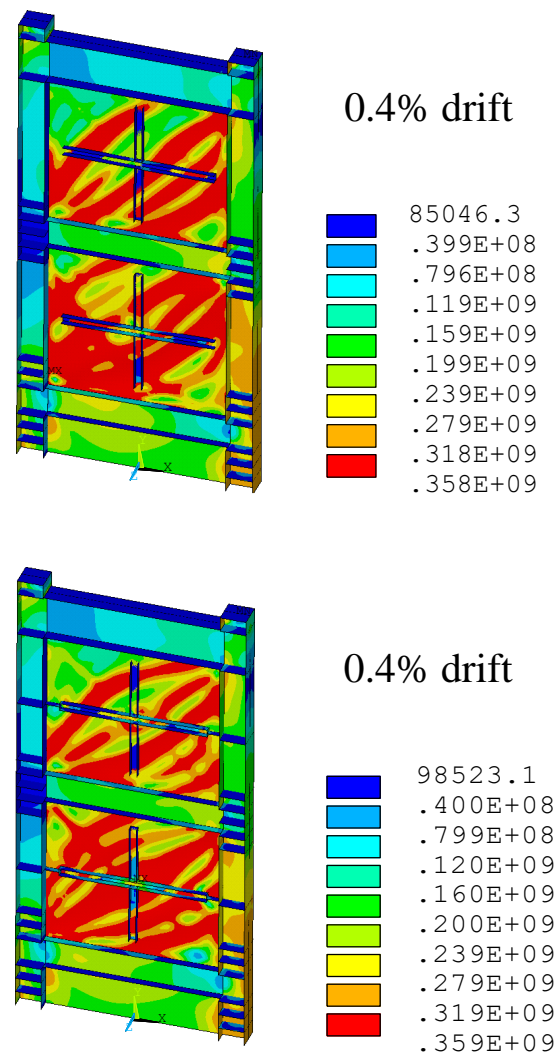
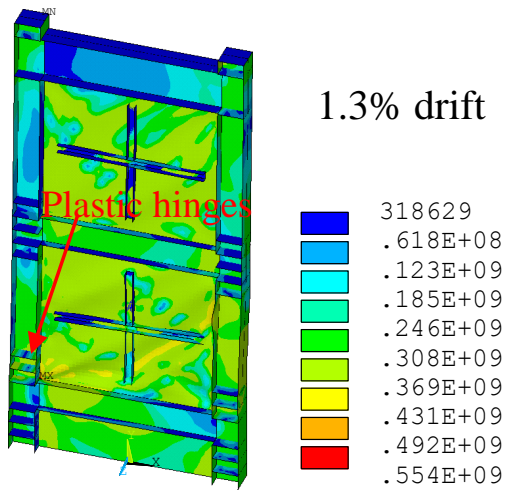

(b)

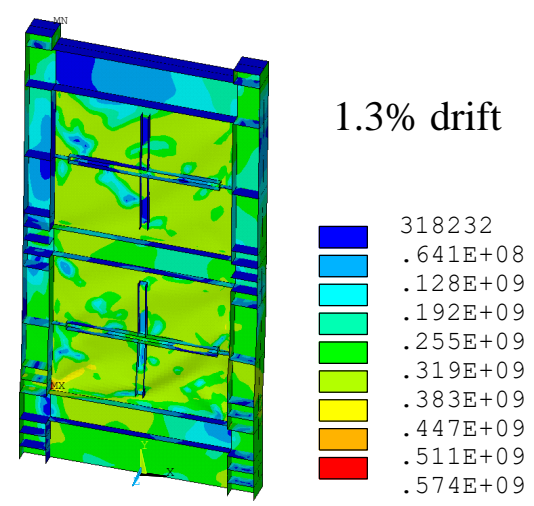

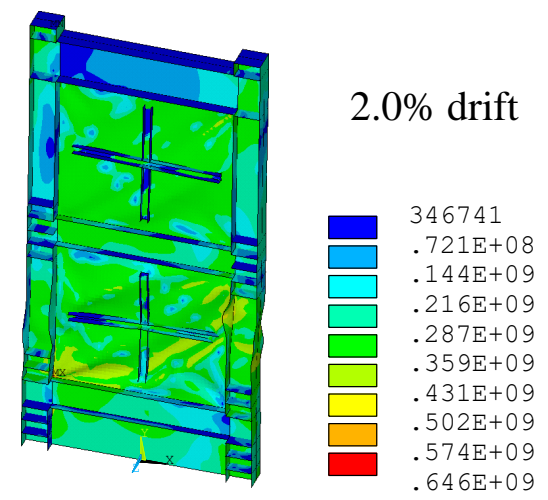

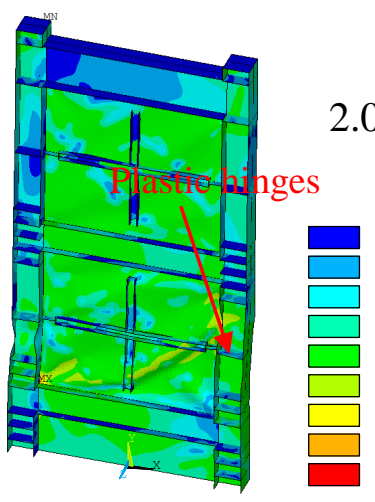

$2.0 \%$ drift

341440

$.749 \mathrm{E}+08$ $.149 \mathrm{E}+09$ $.224 \mathrm{E}+09$ $.298 \mathrm{E}+09$ $.373 E+09$ $.447 \mathrm{E}+09$ $.522 \mathrm{E}+09$ $.597 \mathrm{E}+09$ $.671 \mathrm{E}+09$

(c)

Fig. 17 von Mises stress of FE models (a) NBRP, (b) CBRP and (c) CBRP-TB under different drifts (unit: $\mathrm{Pa}$ )

\subsection{Deformation of columns}

Fig. 18 shows the lateral deformation of east columns against the horizontal displacement for specimens NBRP, CBRP and CBRP-TB. At the initial stage of loading, the lateral deformation of columns changes linearly under the lateral displacement of the frame. The maximum flexural deformation of the first-story column of the specimen NBRP is about $0.2 \%$ of the story height while that of specimen CBRP-TB is $0.04 \%$ of the story height. With the development of the tensile field in the infill steel plate, local inward flexural deformation of the frame columns occurred with occurrence of polygonal lines in Fig. 18. Generally, the occurrence of inward flexural deformation in specimen NBRP is earlier than other two FE models with cross restrainers. Assuming the local flexural deformation of the column comes up to the significant level when the local deformation of the first-story frame column reaches the $0.25 \%$ of the column height, specimens NBRP, CBRP and CBRP-TB show the significant local deformation at the lateral drifts of $0.8 \%, 1.1 \%$ and $1.5 \%$, respectively. Thus, transverse braces are efficient to delay the occurrence of local deformation of columns in SPSW structure. As the buckling of transverse braces, weakening of lateral supporting effect significantly increases the inward flexural deformation of the first-story columns in specimens with transverse braces. In summary, the specimen CBRP-TB has the optimal performance in restraining the inward flexural deformation of the frame columns, followed by specimens CBRP and NBRP. 

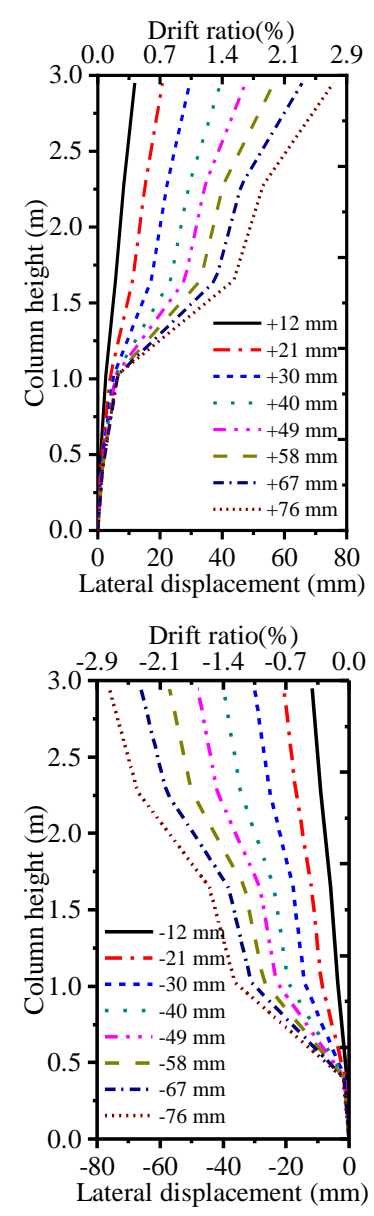

(a)
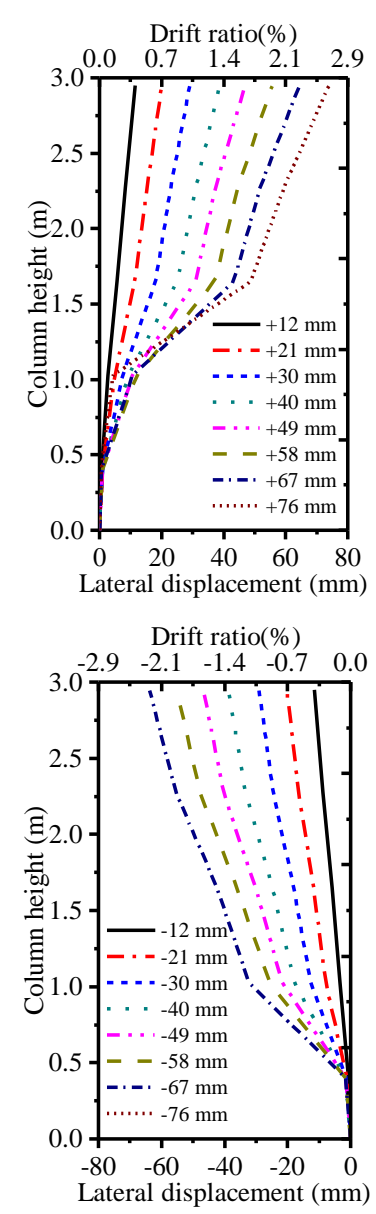

(b)
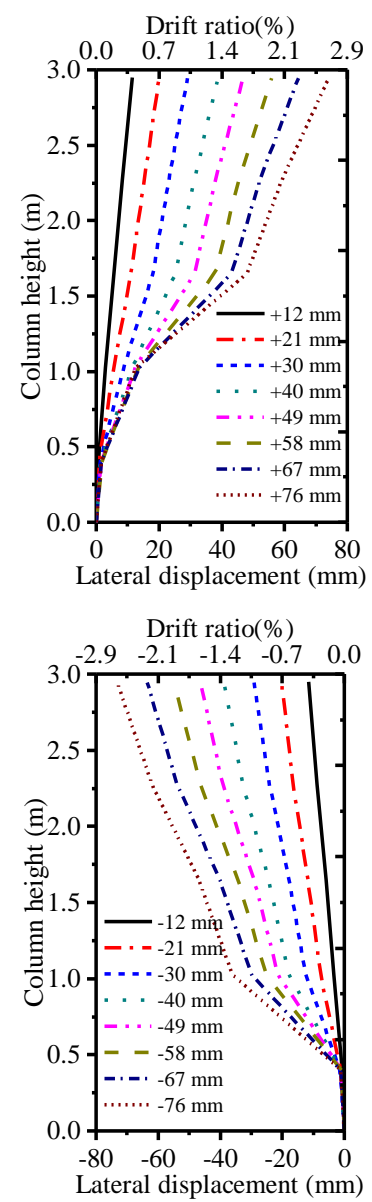

(c)

Fig. 18 Global deformations of columns in SPSW FE models (a) NBRP, (b) CBRP and (c)

\section{CBRP-TB}

Fig. 19 shows the inward flexural deformations of east columns at the first story of SPSW structure for specimens NBRP, CBRP and CBRP-TB under the displacements of $21 \mathrm{~mm}, 67 \mathrm{~mm}$ and $76 \mathrm{~mm}$. At the initial stage of loading (e.g. $21 \mathrm{~mm}$ displacement), specimen NBRP exhibits slightly higher inward flexural deformation of columns than other two FE models with cross restrainers. When the lateral displacement reaches $67 \mathrm{~mm}$, specimen CBRP-TB shows the smallest inward flexural deformation of $11.02 \mathrm{~mm}$, which is $41.5 \%$ lower than that in specimen NBRP. Further increase of lateral displacement to $76 \mathrm{~mm}$, specimen CBRP has the largest inward flexural deformation of column at $20.35 \mathrm{~mm}$. This is probably attributed to the buckling of transverse braces in specimen CBRP. The local deformations of columns in specimens CBRP-TB and NBRP are $39.5 \%$ and $20.0 \%$, smaller than that of specimen CBRP, respectively. Thus, the use of cross restrainers combined with transverse braces is an effective way to restrain the inward flexural deformation of columns in SPSW structure. 


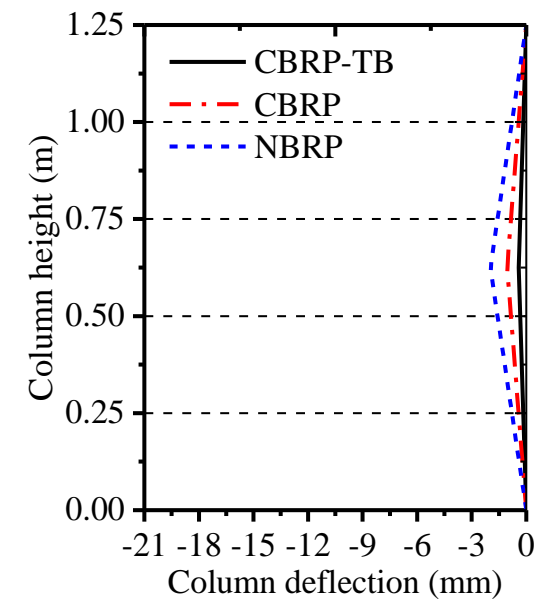

(a)

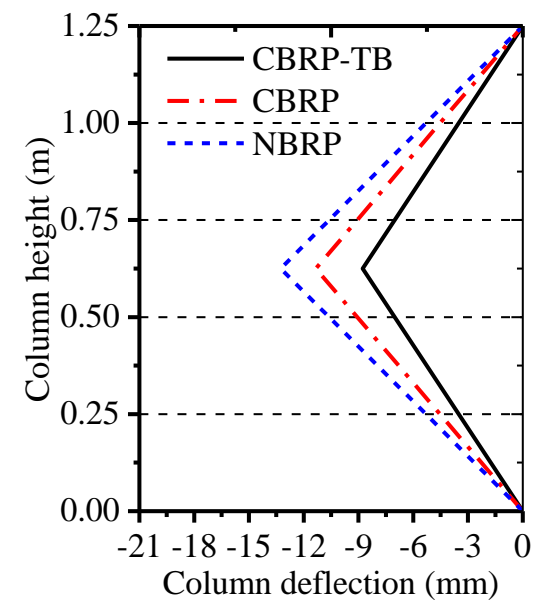

(b)

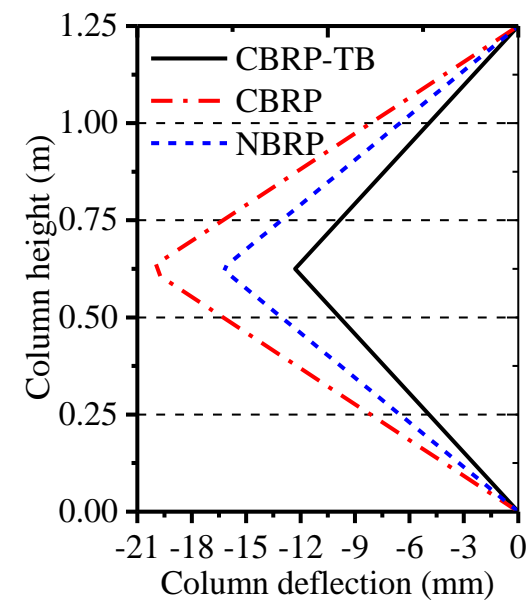

(c)

Fig. 19 Local deformation of the first-story columns in SPSWs at the horizontal displacement of (a) $21 \mathrm{~mm}$, (b) $67 \mathrm{~mm}$ and (c) $76 \mathrm{~mm}$

\subsection{Out-of-plane deformation of steel plates}

Fig. 20 shows the out-of-plane deformation of steel plates for specimens NBRP, CBRP and CBRP-TB at the drift ratio of $2.0 \%$. It is readily seen that the out-of-plane deformations of steel plates in all of specimens mainly occurred at the first story. Specimen CBRP exhibits the highest out-of-plane deformation of infill steel plate, followed by specimens NBRP and CBRP-TB in sequence. Specifically, the maximum out-of-plane deformation of steel plate in specimen CBRP-TB is $10.5 \%$ less than that of specimen CBRP. As seen in Fig. 20(b), out-of-plane deformation of steel plate in specimen CBRP fully diagonally developed in the whole steel plate combined with local buckling within the cell plates. However, cross restrainers with transverse braces change the out-of-plane deformation of steel plate from overall bucking in specimen CBRP into local buckling of the cell plates in specimen CBRP-TB, thus the maximum deformation of the steel plate is reduced. The use of cross restrainers combined with transverse braces is effective in restraining the out-of-plane deformation of infill steel plate in the SPSW structure.

Fig. 21 shows the residual out-of-plane deformation of steel plates in specimens NBRP, CBRP and CBRP-TB after unloading from the drift ratio of 2.0\%. Similarly, the residual out-of-plane deformation of steel plates concentrated at the first story of SPSW structures. For specimen NBRP without stiffeners and braces, it has the maximum residual out-of-plane deformation of steel plate. The maximum residual out-of-plane deformations of steel plates in specimens CBRP-TB and CBRP are $41.3 \%$ and $27.2 \%$ smaller than that of specimen NBRP, respectively. It indicates that the use of transverse braces is more effective in restraining the residual out-of-plane deformation of steel plates. Besides, residual deformation distributions of steel plates in three specimens are different as shown in Fig. 21. The residual deformation of steel plate in specimen NBRP is mainly along the two diagonal directions and the maximum out-of-plane deformation appears at the intersection of two diagonal tension bands on the infill plate. The residual deformation of steel plate in specimen CBRP is dominated by the local buckling of the cell plates, the buckling areas would connect with each other even under the constraint of stiffeners and the maximum deformation occurs in the boundary zones of infill plate between the stiffener ends and the column flanges. The residual 
deformation of steel plate in specimen CBRP-TB also mainly occurs in the cell plates, and the maximum residual out-of-plane deformation concentrates in the middle of the cell plates. Generally, specimen CBRP-TB exhibits the optimal performance in restraining the residual out-of-plane deformation of infill steel plate in SPSW structure.

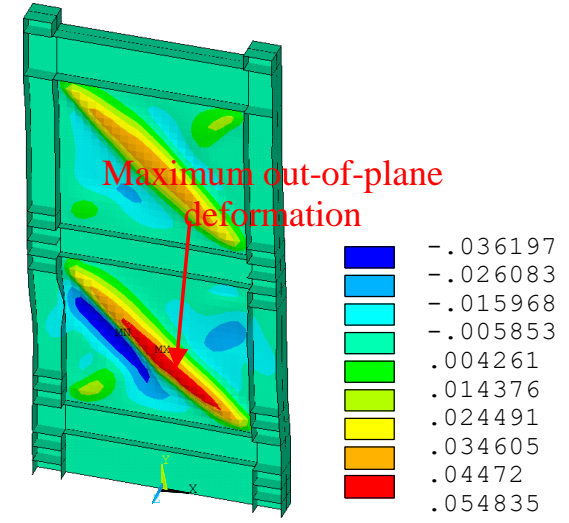

(a)

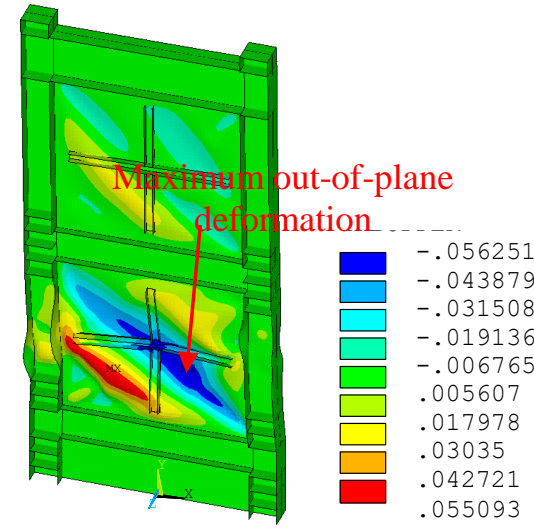

(b)

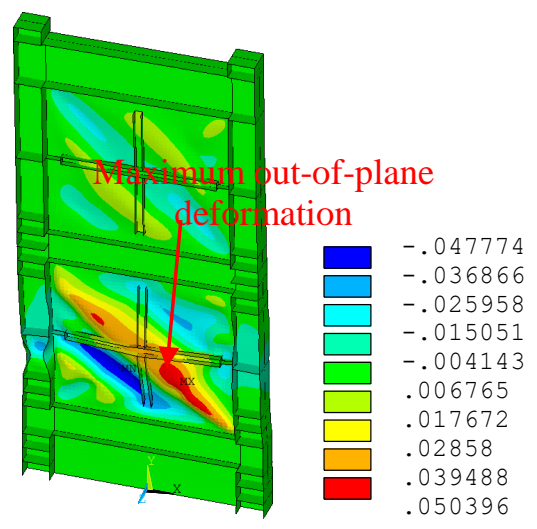

(c)

Fig. 20 Out-of-plane deformation of steel plates in FE models (a) NBRP, (b) CBRP and (c)

CBRP-TB at the drift ratio of $2.0 \%$ (unit: $\mathrm{m}$ )

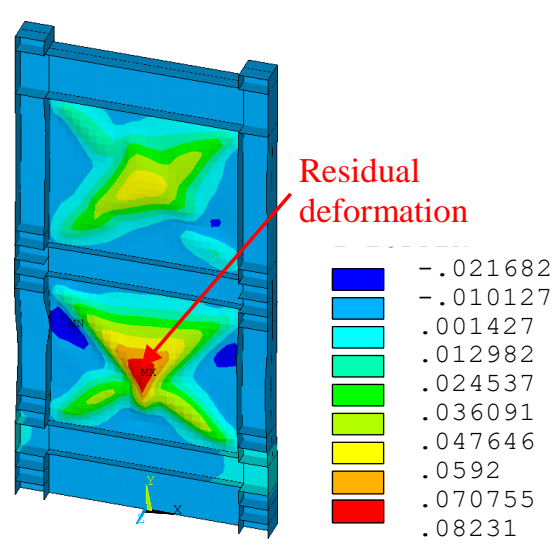

(a)

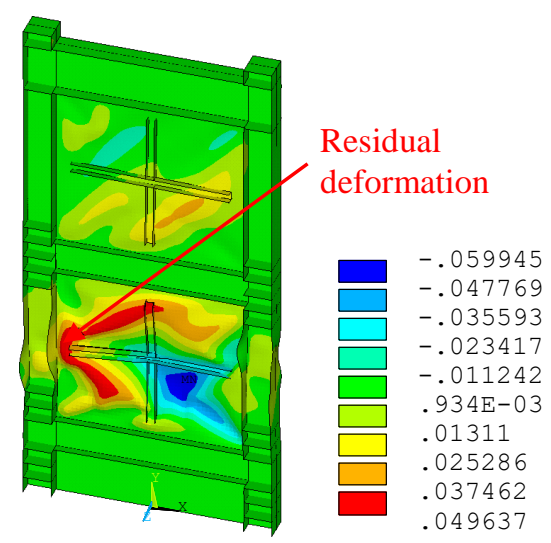

(b)

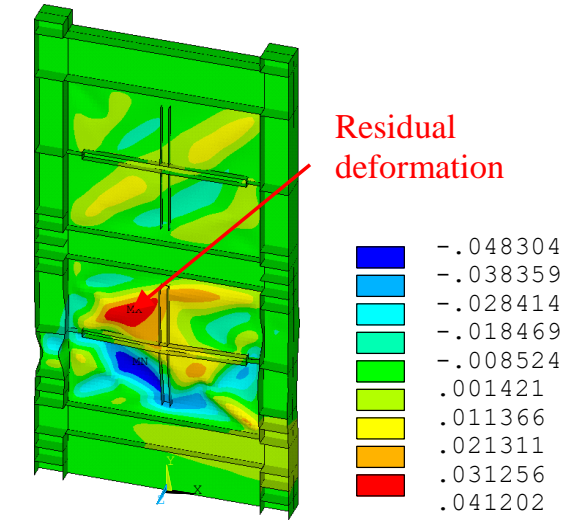

(c)

Fig. 21 Residual out-of-plane deformation of steel plates in FE models (a) NBRP, (b) CBRP and

(c) CBRP-TB after unloading from the drift ratio of $2.0 \%$ (unit: $\mathrm{m}$ ).

\section{Conclusions}

The paper investigates the cyclic performance of cross restrained SPSWs with transverse braces through an experimental study and a finite element analysis. Restrainers with transverse braces are proposed to replace horizontal stiffeners to restrain the buckling of steel plates as well as to alleviate the additional bending moments transferred from the steel plate to the columns. Moreover, the influence of transverse braces on the performance of SPSWs is discussed. Based on the experimental and numerical results, the following conclusions can be drawn.

(1) The use of the cross restrainers combined with transverse braces can enhance the loading capacity, energy dissipation capacity, stiffness and ductility of SPSW structure. For instance, the loading capacity of SPSWs is increased by $15 \%$ after the installation of cross restrainers 
with transverse braces.

(2) Buckling of the infill steel plates in SPSWs can be delayed after incorporating the transverse braces. Connecting transverse braces to the columns enhances the contribution of steel plates in lateral resistance of SPSW structure as it changes the out-of-plane deformation of the infill steel plate from overall buckling of the whole plate in specimen CBRP into local buckling of cell plates in specimen CBRP-TB.

(3) With the incorporation of transverse braces as the substitute of conventional welding stiffeners, the columns can sustain the lateral resistance before the failure of infill steel plates. Plastic hinges in the SPSWs shift from ends of column to the column-brace connection. It is beneficial to enhance the structural performance of SPSWs.

(4) The use of cross restrainers combined with transverse braces is efficient to reduce the maximum bending moment and the in-plane flexural deformation of the columns. The maximum bending moment and in-plane flexural deformation in the first-story columns are reduced by around $40 \%$ and $41.5 \%$, respectively.

(5) The rotation of beam-column connections is reduced in SPSWs with transverse braces, which reduces the stress in the beam-column connection and effectively avoids the damage to the end plates of frame beams.

\section{Acknowledgements}

This study has been supported by research grants from the National Key R\&D Program of China (No. 2017YFC0702303) and the National Natural Science Foundation of China, Young Scientists (Grant No. 51408461). The financial support is greatly acknowledged. Special thanks are also extended to the technical support of the State Key Laboratory at Xi'an University of Architecture \& Technology.

\section{References}

[1] R.G. Driver, G.L. Kulak, D.J.L. Kennedy, A.E. Elwi, Cyclic test of four-story steel plate shear wall, J Struct Eng-Asce 124(2) (1998) 112-120.

[2] S. Sabouri-Ghomi, M Gholhakia, Ductility of thin steel plate shear wall. Asian J of Civil Eng 9(2) (2008) 2069-2077.

[3] J.G. Yu, X.T. Feng, B. Li, J.P. Hao, A. Elamin, M.L. Ge, Performance of steel plate shear walls with axially loaded vertical boundary elements, Thin Wall Struct 125 (2018) 152-163.

[4] G. Chen, Y. Guo, Z. Fan, Y. Han, Cyclic test of steel plate shear walls. J Building Struct 25(2) (2004) 19-26. (in Chinese)

[5] Mark Sarkisian, Dasui Wang, Sam Lee, et al. World's tallest steel shear walled building. CTBUH Journal, 1(2011), 29-33.

[6] H.R. Habashi, M.M. Alinia, Characteristics of the wall-frame interaction in steel plate shear walls, Steel Constr 66(2) (2012) 150-158.

[7] A.S. Lubell, H.G.L. Prion, C.E. Ventura, M. Rezai, Unstiffened steel plate shear wall performance under cyclic loading, J Struct Eng-Asce 126(4) (2000) 453-460.

[8] C.H. Li, K.C. Tsai, C.H. Lin, P.C. Chen, Cyclic tests of four two-story narrow steel plate shear 
walls. Part 2: Experimental results and design implications, Earthq Eng Struct D 39(7) (2010) 801-826.

[9] Y. Guo, G. Chen, Y. Miao, Elastic buckling behavior of steel plate shear wall with cross or diagonal stiffeners. Eng Mech 23(2) (2006) 84-91. (in Chinese)

[10]M.A. Sigariyazd, A. Joghataie, N.K.A. Attari, Analysis and design recommendations for diagonally stiffened steel plate shear walls, Thin Wall Struct 103 (2016) 72-80.

[11]W. Zhao, Q.Y. Yang, G.S. Tong, Stiffener stiffness and elastic buckling stress of steel plate shear wall, Eng Mech 27(6) (2010) 15-23. (in Chinese)

[12]JGJ/T380-2015, Technical specification for steel plate shear walls. Beijing: China Architecture \& Building Press, 2016. (in Chinese)

[13]J.Y. Yang, G.S. Tong, L. Zhang, Research of elastic buckling of steel shear walls stiffened by vertical tubes under nonuniform compression, Eng Mech 32(11) (2015) 132-139. (in Chinese)

[14]E. Alavi, F. Nateghi, Experimental study on diagonally stiffened steel plate shear walls with central perforation, J Constr Steel Res 89 (2013) 9-20.

[15]S. Sabouri-Ghomi, S. Mamazizi, Experimental investigation on stiffened steel plate shear walls with two rectangular openings, Thin Wall Struct 86 (2015) 56-66.

[16]H.C. Guo, J.P. Hao, Y.H. Liu, Behavior of stiffened and unstiffened steel plate shear walls considering joint properties, Thin Wall Struct 97 (2015) 53-62.

[17]S.S. Jin, J.L. Bai, J.P. Ou, Seismic behavior of a buckling-restrained steel plate shear wall with inclined slots, J Constr Steel Res 129 (2017) 1-11.

[18] W.Y. Liu, G.Q. Li, J. Jiang, Mechanical behavior of buckling restrained steel plate shear walls with two-side connections, Eng Struct 138 (2017) 283-292.

[19]M.W. Wei, J.Y.R. Liew, Y. Du, X.Y. Fu, Seismic behavior of novel partially connected buckling-restrained steel plate shear walls, Soil Dyn Earthq Eng 103 (2017) 64-75.

[20]K.C. Tsai, C.H. Li, C.H. Lin, C.Y. Tsai, Y.J. Yu, Cyclic tests of four two-story narrow steel plate shear walls-Part 1: Analytical studies and specimen design, Earthq Eng Struct D 39(7) (2010) 775-799.

[21]American Institute of Steel Construction (AISC). Seismic Provisions for Structural Steel Buildings. Chicago, IL.2016.

[22] National Standard of the People's Republic of China, JGJ/T101-2015, Specification for Seismic Test of Buildings, China Architecture \& Building Press, Beijing, 2015 (in Chinese).

[23]B. Li, E.S.S. Lam, B. Wu, Y.Y. Wang, Experimental investigation on reinforced concrete interior beam-column joints rehabilitated by ferrocement jackets, Eng Struct 56 (2013) 897-909. 